\title{
Ventilator Graphics: Scalars, Loops, \& Secondary Measures
}

\author{
Amanda M Dexter and Kimberly Clark
}

\author{
Introduction \\ Ventilator Graphics: The Present \\ Applied Respiratory Physiology \\ Ventilator Design \\ Ventilator Graphics \\ Scalars \\ Stress Index \\ Respiratory Mechanics \\ Plots \\ Inflection Points \\ Work of Breathing \\ Asynchronies \\ Ventilator Graphics: The Future \\ Conclusions
}

\begin{abstract}
Ventilator graphic monitoring is common in ICUs. The graphic information provides clinicians with immediate clues regarding patient-ventilator interaction and ventilator function. These display tools are aimed at reducing complications associated with mechanical ventilation, such as patientventilator asynchrony. It is also useful to assess respiratory mechanics in mechanically ventilated patients using both scalar and plot displays on the ventilator. Additional information can be gained by observing secondary ventilator measures including stress index, inflection points, and work of breathing. Ventilator graphics impact mechanical ventilation management through optimizing effectiveness of patient care and enhancing promptness of clinician response. Despite being a valuable asset in providing high-quality patient care, many bedside clinicians do not have a thorough understanding of ventilator graphics. Mastery of ventilator graphics interpretation is key in managing patients who are receiving ventilatory support. Key words: ventilator graphics; ventilator scalars; mechanical ventilation; stress index; ventilator plots; inflection points; work of breathing; asynchronies; respiratory mechanics. [Respir Care 2020;65(6):739-759. (C) 2020 Daedalus Enterprises]
\end{abstract}

\section{Introduction}

Interpretation of ventilator graphics is a critical component of the management of acute and chronically ill patients

Ms Dexter is affiliated with the Department of Kinesiology, Respiratory Care Program, University of North Carolina at Charlotte, Charlotte, North Carolina. Dr Clark is affiliated with the Department of Kinesiology, Respiratory Care Program, University of North Carolina at Charlotte, Charlotte, North Carolina. who are receiving mechanical ventilation. Failure to properly monitor and identify issues related to respiratory mechanics by means of ventilator graphics can lead to complications such as patient-ventilator asynchrony, prolonged time on mechanical ventilation, longer hospital stay,

The authors have disclosed no conflicts of interest.

Ms Dexter presented a version of this paper at the 58th RESPIRATORY CARE Journal Conference, held June 10-11, 2019, in St. Petersburg, Florida. 


\section{VENTILATOR GRAPHICS}

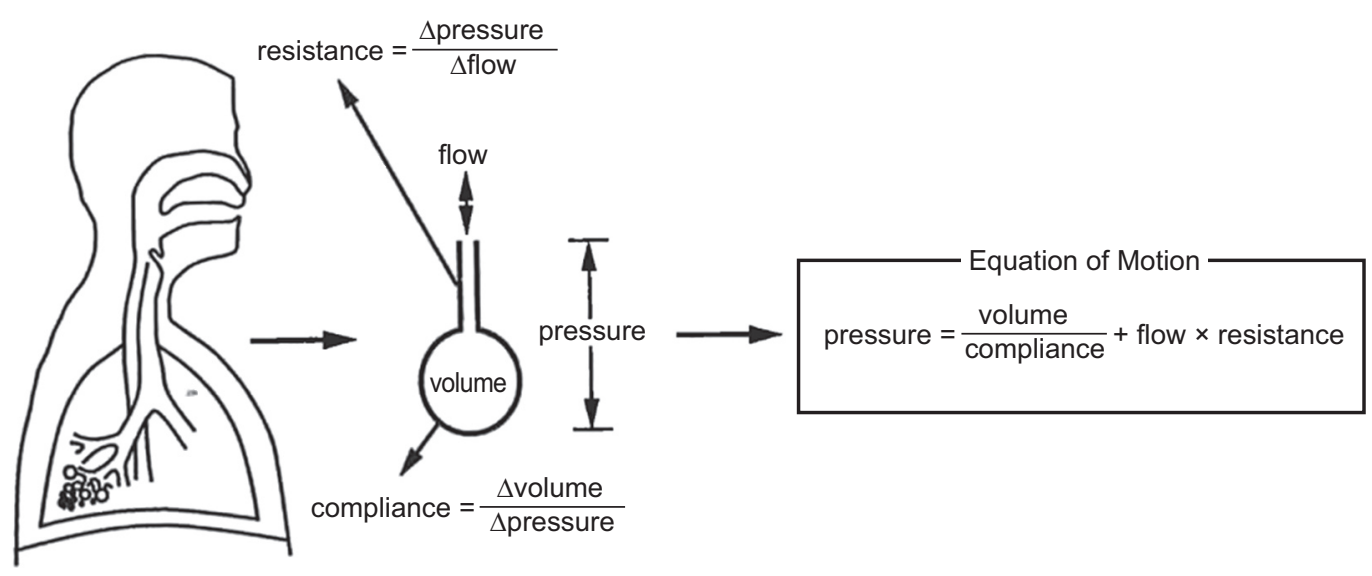

Fig. 1. Single-compartment model of the respiratory system. From Reference 9.

increased costs, and even death. Efforts have been made over the years to improve the quality of ventilator technology. Although many manufacturers have sought to implement easy-to-understand ventilator displays, many health care professionals are not properly trained on analysis of ventilator graphics. The ability of bedside clinicians to adequately interpret and manage patients on the basis of ventilator graphics has received much attention due to the associated increase in morbidity and mortality among mechanically ventilated patients. Analysis of ventilator graphics may play a significant role in the optimization of patient-ventilator interaction. The use of ventilator graphics such as scalars, plots, stress index, inflection points, and work of breathing (WOB) have been described in the literature as ways to improve care management in patients on mechanical ventilation. This paper will review ventilator graphics, their physiologic use at the bedside, and their known impact on management strategies for mechanically ventilated patients.

\section{Ventilator Graphics: The Present}

The management of critically ill patients requiring mechanical ventilation consumes substantial resources and time. These patients need intricate care and are at high risk of adverse events. Inadequate monitoring of ventilator graphics may pose a significant danger to patient safety, leading to complications such as asynchrony and increased WOB, as well as detrimental outcomes. ${ }^{1}$ Training for the entire patient care team in the ongoing management of patients on invasive and noninvasive ventilation is

Correspondence: Amanda M Dexter MSc RRT RCP CHSE, University of North Carolina at Charlotte, Department of Kinesiology, 9201 University City Blvd, Belk Gym 221, Charlotte, NC 28223. E-mail: adexter1@uncc.edu.

DOI: $10.4187 /$ respcare.07805 generally limited; in addition, most clinicians have little, if any, formal education on the interpretation of ventilator waveforms. The monitoring of ventilator graphics presents the opportunity to apply respiratory physiology at the bedside and to use science to improve patient care. This information is unfortunately not commonly integrated into everyday practice for many clinicians. Thus, pertinent information is available on the ventilator screen, and clinicians pay little attention beyond the digital displays. Ventilator graphics are seldom given the recognition they deserve, and in some regards this advanced technology has surpassed clinicians' ability to properly use the information. ${ }^{2}$ Despite these setbacks, graphic interpretation is key in managing patients receiving ventilatory support. In 2005, Durbin ${ }^{3}$ suggested clinicians should have frequent exposure to ventilator graphics to improve comfort and competence. Ventilator graphics constitute a valuable bedside tool, and a thorough understanding of mechanical ventilation can influence the quality of care provided in ICUs. Standardized monitoring of ventilator graphics can be useful to improve patient-ventilator synchrony, reduce WOB, improve patient comfort, and decrease mortality outcomes in mechanically ventilated patients. ${ }^{4}$

\section{Applied Respiratory Physiology}

To understand ventilator graphics, clinicians need to consider a model of the respiratory system. Figure 1 represents the complex system of airways and lung units in a simpler format that is easier to understand. The most common model for this purpose is known as a single-compartment model of the respiratory system. ${ }^{5-9}$ The function of this model is to allow clinicians to make measurements of the 3 most common ventilator parameters and use them to describe the mechanical properties of the respiratory system that are useful for understanding both patient physiology and patient-ventilator interaction. There are 2 basic 
A

B

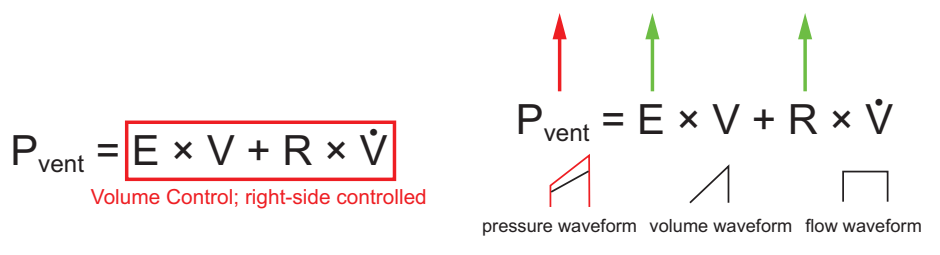

C
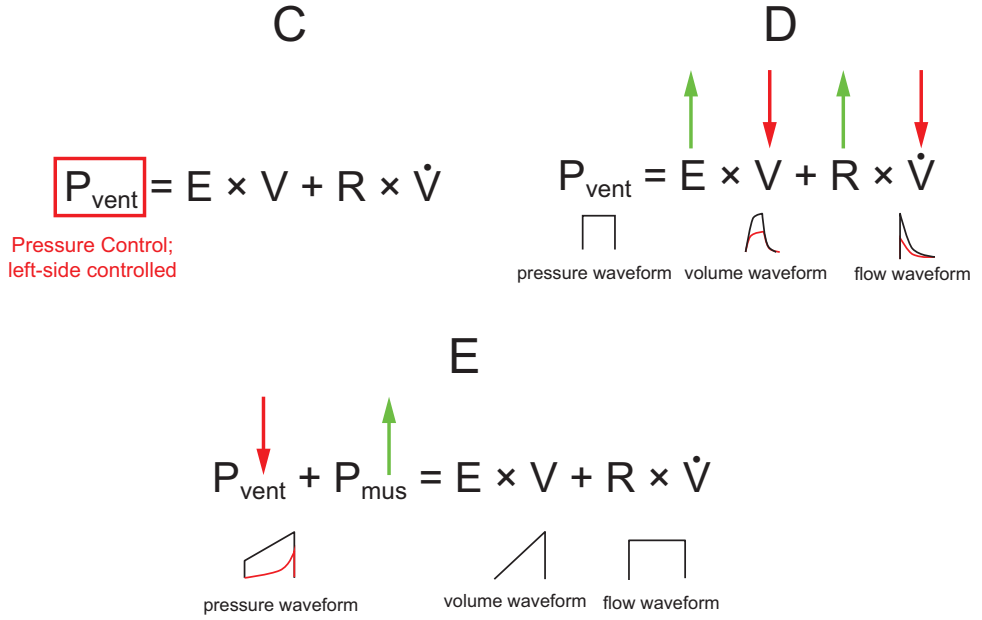

Fig. 2. Mechanical ventilation mathematical interpretations. (A) Volume control continuous mandatory ventilation. (B) Fixed settings and affected changes during volume control continuous mandatory ventilation; changes in respiratory mechanics affect the pressure scalar. (C) Pressure control continuous mandatory ventilation. (D) Fixed settings and affected changes during pressure control continuous mandatory ventilation; changes in respiratory mechanics affect the volume and flow scalars. (E) Scalar distortion or patient-ventilator asynchrony in volume control continuous mandatory ventilation. $P_{\text {vent }}=$ ventilation pressure; $E=$ respiratory system elastance; $V=$ volume; $R=$ airway resistance; $\dot{\mathrm{V}}=$ flow over time.

mechanical properties of interest. The first is resistance, defined as the ratio of pressure change to flow change, and the second is elastance, defined as the ratio of pressure change to volume change. ${ }^{5,6,10,11}$

Clinicians must also understand that the respiratory system model can take several forms: it can be a graphic (Fig. 1), it can be physical (ie, the straw and balloon model), or it can be mathematical (ie, expressed in terms of pressure, volume, and flow as functions of time). The most useful form of the single-compartment model of the respiratory system is the mathematical form, which is called the equation of motion for the respiratory system: $P_{\text {vent }}=(E \times V)+$ $(\mathrm{R} \times \dot{\mathrm{V}})$, or $\mathrm{P}_{\mathrm{vent}}=(\mathrm{V} / \mathrm{C})+(\mathrm{R} \times \dot{\mathrm{V}})$, where $\mathrm{P}_{\text {vent }}$ is the pressure generated by the ventilator, $\mathrm{E}$ is the respiratory system elastance, $\mathrm{V}$ is volume over time, $\mathrm{R}$ is airway resistance, $\dot{V}$ is flow over time, and $\mathrm{C}$ is respiratory system compliance. This is the single most important concept in understanding ventilator graphics and patient-ventilator interactions. It begins with Newton's third law of motion, which states that the pressure the ventilator exerts is opposed by an equal and opposite pressure created by the patient. ${ }^{12}$ The mathematical equation can then be expanded on the right side to show that pressure created by the patient actually has 2 factors, elastance and airway resistance. ${ }^{5,6,10}$
Using the common definitions for elastance and airway resistance, the equation can be further expanded to show the relationship among the 3 most common ventilator parameters (ie, pressure, volume, and flow as functions of time) and among the 2 respiratory mechanics factors (ie, elastance and airway resistance). The equation of motion is also the theoretical basis for defining the pressure control continuous mandatory ventilation and volume control continuous mandatory ventilation modes of mechanical ventilation (Fig. 2) ${ }^{5,6,10}$ Pressure control continuous mandatory ventilation controls the left side of the mathematical equation. In terms of ventilator settings, controlling pressure means that the clinician sets the shape of the pressure waveform. In contrast, volume control continuous mandatory ventilation means that the clinician controls the right side of the equation. This implies that the clinician sets the shape of both the tidal volume $\left(\mathrm{V}_{\mathrm{T}}\right)$ waveform and the inspiratory flow waveform. Furthermore, the equation of motion helps clinicians interpret bedside observations of ventilator graphics. In volume control continuous mandatory ventilation, if either elastance or airway resistance increases, peak inspiratory pressure (PIP) increases. In pressure control continuous mandatory ventilation, if either elastance or airway resistance increases, volume and flow 


\section{VENTILATOR GRAPHICS}

change. In clinical practice, spontaneous patient efforts also need to be taken into account. This is accomplished by adding a term to the left side of the equation: $P_{\text {vent }}+P_{\text {mus }}=$ $(\mathrm{E} \times \mathrm{V})+(\mathrm{R} \times \dot{\mathrm{V}})$, where $\mathrm{P}_{\text {mus }}$ is muscle pressure or the spontaneous patient effort. ${ }^{5,6,10}$ This represents the pressure generated by the muscles involved in spontaneous breathing, such as the diaphragm and intercostal muscles. If muscle pressure is above zero, spontaneous breathing is present and there will be effects on pressure, volume, or flow, depending on the mode of mechanical ventilation. ${ }^{5,6,10}$ Adding the concept of muscle pressure helps clinicians understand other observations at the bedside using ventilator graphics. In volume control continuous mandatory ventilation, the right side of the equation must remain constant. Thus, if the patient makes a spontaneous effort, defined as an increase in muscle pressure, ventilator pressure $\left(\mathrm{P}_{\mathrm{vent}}\right)$ must decrease to keep the sum of the terms on the left side of the equation constant. Graphically, this demonstrates a distortion of the pressure waveform, which is a form of patient-ventilator asynchrony.

Patient-ventilator asynchrony is caused by various factors involving a mismatch between time, flow, volume, or pressure demands of the patient's respiratory system and the ventilator. ${ }^{13}$ The most common causes of patient-ventilator asynchrony are related to trigger sensitivity, flow delivery, and cycle-off criteria, which can have profound effects on the neural control of breathing. ${ }^{14}$ Neural control of breathing is regulated by chemoreceptors and lung receptors to sense changes in the chemical composition of the blood and other fluids (ie, $\mathrm{pH}, \mathrm{P}_{\mathrm{O}_{2}}, \mathrm{P}_{\mathrm{CO}_{2}}$ ) and changes in mechanical properties (eg, muscle loading, overdistention), respectively. For example, delayed or missed triggering can cause excessive muscle loading leading to discomfort, increased WOB, and dyspnea. ${ }^{14-15}$ In 2006, Thille et $\mathrm{al}^{16}$ assessed the incidence of patient-ventilator asynchrony during continuous mandatory ventilation in 62 subjects. Nearly one fourth of the subjects experienced a high incidence of patient-ventilator asynchrony events primarily attributed to ineffective triggering and double-triggering. Ineffective triggering was observed most often and was associated with a less sensitive inspiratory trigger, a higher level of pressure support, a higher $\mathrm{V}_{\mathrm{T}}$, and a higher $\mathrm{pH}$. In this group of subjects, missed triggers were primarily a consequence of intrinsic PEEP. In addition, a high incidence of patient-ventilator asynchrony was related to a longer duration of mechanical ventilation. Choice of ventilator mode and settings are factors that affect patient-ventilator asynchrony. ${ }^{13}$ Optimum patient-ventilator interaction should be guided by choosing the ventilator mode and settings that increase the patient's control of ventilation. Advances in mechanical ventilation technology have introduced new modes and modifiable settings to improve patient-ventilator interaction. Proper interpretation of ventilator graphics and thus management of mechanically ventilated patients requires clinicians to have a comprehensive understanding of respiratory physiology, a patient's respiratory function, and the fundamentals of mechanical ventilation.

\section{Ventilator Design}

The concept of modern mechanical ventilation can be traced back to the mid-16th century with Vesalius' description of applying positive-pressure ventilation. ${ }^{17}$ However, advances in developing mechanical ventilation stalled until the middle to late 19th century due to a lack of understanding of physiological principles. Negative-pressure ventilation became the predominant means of providing ventilatory assistance by using subatmospheric pressure delivered around the body. ${ }^{17-18}$ The use of negative-pressure ventilation peaked during the poliomyelitis epidemic in the mid-20th century with the development of the iron lung. However, the limitations and problems associated with negative-pressure ventilation made it ineffective for maintaining consistent ventilation. The predominant focus on providing ventilatory support began to shift with the increased physiologic understanding of gas exchange, which ushered in a new era of invasive positive-pressure ventilators in the ICU. ${ }^{17}$ Over the past $60 \mathrm{y}$, the evolution of ventilator design has dramatically improved from providing only machine-triggered, volume control ventilation to modern advances of microprocessorcontrolled systems designed to increase the patient's control of ventilation through improved patient triggering, flow delivery, and modes of ventilation that can automatically adjust ventilatory parameters in response to varying patient conditions. ${ }^{17,19}$

In 2011, Kacmarek $^{18}$ suggested that various factors could be used to determine the usefulness of new design features such as improved safety, decreased risk of lung injury, more effective oxygenation and ventilation, more efficient patient weaning, and improved patient-ventilator synchrony. Other important factors that should be considered include monitoring capabilities and accurate ventilatorderived data that are easy to understand for effective ventilator management. Today's ventilators are designed to capture all relevant ventilation variables (eg, flow, pressure, volume) using actuators, sensors, and digital-signal processing algorithms to deliver the desired ventilation mode and then display that information back to us. ${ }^{19-20}$

Over the past decade, the area of ventilator design has transformed. Today, ICU ventilators are expected to provide information in a convenient format. Ventilator technology has the capability to design and manufacture the efficient capture and translation of these variables. The varying signals and data communicated are important to the appropriate management of an ICU ventilator. However, in 2005, Sanborn ${ }^{20}$ raised an issue regarding the required quality of this information, which was linked to the concept of measurement versus estimation. Sanborn ${ }^{20}$ 


\section{VENTILATOR GRAPHICS}

emphasized that the accuracy of ventilator-derived data and graphics is more estimation than precise measurement. Succinctly, high accuracy comes at a high price, while good estimation comes at a reasonable price. Accuracy, with regard to ventilator graphics, should always be a focus of attention. Sanborn ${ }^{20}$ argued that although accuracy of the ventilation variables should always be the focus of attention, the quality of ventilator-derived data are more in line with a sufficiently reliable estimation than with a highly accurate measurement.

Technological advances and sophisticated capabilities often outpace what many clinicians can fully understand and use. With consideration of evaluating factors that determine the usefulness of new design features, the reliability of the ventilator-derived data, and the ability to use the information for appropriate ventilator management, have manufacturers hit a technological ceiling?

In 2009, Thille et $\mathrm{al}^{21}$ conducted a bench study comparing new-generation (circa 2006) ICU ventilators to those that were available in the year 2000. The investigators team examined trigger functionality, pressurization capacity, and accuracy of pressure measurements and expiratory resistance during pressure support ventilation and volume control ventilation. In summary, the new ventilators did not outperform older ventilators. Some ventilators exhibited poorer performance characteristics than the older machines, suggesting that a potential technological ceiling may have been reached. ${ }^{21}$ Similarly, Marjanovic et $\mathrm{al}^{22}$ aimed to provide a comprehensive evaluation of 6 recent ICU ventilators, evaluating both their technological performance and their ergonomics. The researchers noted that, despite the ventilators having similar technical performance and functional design, such features were considered poor, thus increasing the risks of misuse and adverse events. Although huge efforts have been made to improve technical issues of ventilators, increasing complexity may actually result in design errors. Not only are capabilities underutilized, but main functions are often improperly handled. In addition, quality-control factors can affect the performance of ventilators. Govoni et $\mathrm{al}^{23}$ conducted a multi-center quality-control study on the performance of ICU ventilators. The findings suggested that overall performance was good, but there was considerable performance variability; in some cases, substantial errors were found, especially in volume- and peak pressure-related variables. Ventilator graphics provide a visual display of the patient-ventilator interaction, and ventilator graphic interpretation is an important tool for clinicians to use in assessing changes in respiratory mechanics and response to therapy and in troubleshooting problems.

In 2015, Garnier et $\mathrm{al}^{24}$ conducted bench studies to determine the accuracy of 13 new ventilators to deliver chosen parameters in various conditions. Results showed that, despite numerous improvements, the delivered $V_{T}$, PEEP, and pressure support levels were less reliable than the devices displayed, suggesting that inconsistencies and advancements among modern ventilators need to be investigated. ${ }^{24}$ However, in a more recent bench study, Delgado et $\mathrm{al}^{25}$ tested 7 turbine mid-level critical care ventilators for performance in pressurization and trigger capacities. All ventilators worked properly, but the newest ventilators had higher pressurization capacity and better trigger performance compared to older turbine models. Although technical performance is clearly important, other aspects of functionality play a significant role in determining performance.

Another difficulty with modern ventilator designs is the lack of standardized vocabulary and added definitions of novel ventilator modes without disclosed algorithms, which can lead to ambiguity and confusion. ${ }^{26}$ Therefore, equipment-specific training is necessary to ensure clinical competency and to avoid inappropriate generalizations.

Past improvements in mechanical ventilators were due to the combination of physiology, medicine, and engineering concepts and tools. As the complexity of modern ventilators continues to increase, advanced development and design strategies must be carried out through an interdisciplinary approach. The knowledge and expertise of bioengineers and various clinicians should be joined. Sufficient education on the design and fabrication of mechanical ventilators, patients' respiratory pathophysiology, use of mechanical ventilation, and technological issues will be necessary. Patients' needs are changing, and optimum ventilation management is required to support the instabilities of contemporary respiratory disorders.

\section{Ventilator Graphics}

To understand cardiac physiology, clinicians study electrocardiograms and blood pressure waveforms; in a similar manner, clinicians must understand ventilator graphics to assess respiratory mechanics. Although ventilator graphics and respiratory mechanics measurements are provided by all modern ventilators, this information is not yet commonly incorporated into everyday ICU practice. As such, clinicians need to find ways to simplify ventilator graphics and explain its use as a bedside tool for better assessment of patient status and therapeutic evaluation, and as guidance for the management of a patient's condition. ${ }^{27}$ Dhaliwal et $\mathrm{al}^{27}$ suggested a stepwise approach for rapid interpretation of ventilator graphics. This approach outlines 6 steps to simplify ventilator graphics and explain its use for clinical application (Table 1). ${ }^{27}$ The first step is to identify the type of breath: pressure or volume. A breath is defined in terms of the shape of the flow-time scalar. The second step is to differentiate the pulmonary measurements, ie, the assessment of respiratory mechanics play a central role in the management of critically ill patients on mechanical ventilation. The third step is to interpret the ventilator plots; the concept of lung-protective ventilation has made analysis 


\section{VENTILATOR GRAPHICS}

Table 1. Six Steps for Interpretation of Ventilator Graphics

\begin{tabular}{|c|c|}
\hline Step & Description/Application \\
\hline Identify the type of breath. & Volume or pressure. \\
\hline Differentiate the pulmonary measurements. & $\begin{array}{l}\text { The assessment of respiratory mechanics plays a central role in the management of critically } \\
\text { ill patients on mechanical ventilation. }\end{array}$ \\
\hline Interpret the ventilator plots. & $\begin{array}{l}\text { The concept of gentle ventilation, or avoiding ventilator-induced lung injury, has made } \\
\text { analysis and careful monitoring of pressure-volume and flow-volume plots an integral part } \\
\text { of optimal care management. }\end{array}$ \\
\hline $\begin{array}{l}\text { Identify display images of the common modes of } \\
\text { mechanical ventilation. }\end{array}$ & $\begin{array}{l}\text { All modes can be divided into } 1 \text { of } 3 \text { control variables: pressure, volume, or time; the vast } \\
\text { majority of modes are either volume control or pressure control. }\end{array}$ \\
\hline Interpret inspiratory and expiratory graphics. & Graphical displays are informative in assessing the adequacy of ventilatory support provided. \\
\hline Identify signs of asynchrony. & $\begin{array}{l}\text { Asynchrony is disharmony in the patient-ventilator interaction, which can lead to } \\
\text { deleterious effects; clinicians must be able to identify and understand asynchrony so that } \\
\text { necessary interventions can be performed to optimize patient care. }\end{array}$ \\
\hline
\end{tabular}

From Reference 27.

and careful monitoring of pressure-volume (P-V) and flowvolume plots an integral part of management. The fourth step is to identify the display images used in common modes of mechanical ventilation. All modes can be divided into 1 of 3 control variables: pressure, volume, and time; however, the vast majority are either volume control or pressure control. The fifth step is to interpret the inspiratory and expiratory graphics, which are informative in assessing the adequacy of ventilatory support provided. The last step is to identify signs of asynchrony in the patient-ventilator interaction, which leads to deleterious effects. Clinicians must be able to identify and understand asynchrony so that necessary interventions can be performed to optimize patient care. $^{27}$

Graphic displays of ventilator data provide information on a patient's lung mechanics and the patient-ventilator interaction. However, graphics can also be enabled to help clinicians identify ventilator dysfunction. Several case studies discuss how ventilator graphics alone have helped diagnose problems with a ventilator system and allowed for appropriate initiatives to be taken. ${ }^{28-30}$ In a case study presented by Prielipp et al ${ }^{28}$ clinical staff faced unexpected consequences when an unfamiliar ventilator was used for a hemodynamically unstable postoperative patient in the ICU. Fortunately, a rapid ventilator graphics assessment identified the problem as a faulty exhalation valve. Following the incident, the ICU team implemented a standardized evaluation processes to effectively reduce errors, improve troubleshooting procedures, and recycle obsolete medical equipment. In 2011, Krishna Kumar et $\mathrm{al}^{29}$ discussed a ventilator malfunction case study involving inappropriate alarm settings and adverse functional features. Graphic analysis and timely action by the clinical staff prevented a major catastrophe. Sripriya et $\mathrm{al}^{30}$ presented 2 similar case studies on the usefulness of ventilator graphics analysis in detecting ventilator dysfunction. In both cases, the ventilator graphics permitted clinicians to quickly recognize and troubleshoot faulty ventilator equipment (ie, a malfunctioning expiratory valve and a faulty expiratory flow sensor), enabling them to take timely corrective actions. The graphic displays provided clues well beyond that of mere numbers. In all of these cases, the breath-tobreath information provided was an invaluable tool that was utilized to provided optimum care of the ventilated patient. ${ }^{28-30}$ Whenever ventilator parameter changes are required, a systematic approach incorporating ventilator graphics is essential for troubleshooting. Patient-related problems need to be quickly differentiated from ventilatorrelated problems. When equipment dysfunction is suspected, clinicians should have the knowledge and skills to troubleshoot the cause. Observing both the scalars and plots simultaneously is important so that any problem can be easily detected and correlated between graphs to validate the findings. Early analysis and correction of device dysfunction, via the incorporation of ventilator graphics, can decrease morbidity in some cases. ${ }^{28-30}$

A primary role of ventilator graphics is for the detection of patient-ventilator interaction. Identifying patient-ventilator asynchronies using graphic analysis is a noninvasive and reliable method that has a good correlation with other more invasive methods, such as esophageal pressure monitoring or electrical activity of the diaphragm $\left(\mathrm{EA}_{\mathrm{di}}\right)$ signaling. ${ }^{31}$ Even with advancements in ventilator design, asynchronies continue to be difficult to detect. A study by Rolland-Debord et $\mathrm{al}^{32}$ compared the prevalence of asynchrony according to 2 methods of detection: a visual inspection of ventilator graphics using pressure support ventilation, and $\mathrm{EA}_{\mathrm{di}}$ using neurally adjusted ventilatory assist. The authors reported that the prevalence of asynchrony was higher when monitoring with the $\mathrm{EA}_{\mathrm{di}}$ method compared to conventional monitoring with ventilation graphics. ${ }^{32}$ Additionally, although patient-ventilator 


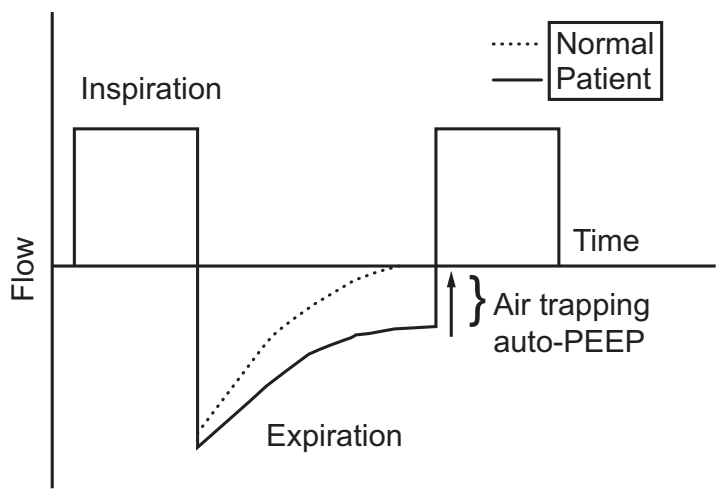

Fig. 3. Flow-time scalar showing air trapping. From Reference 37.

asynchronies can be detected through graphic analysis, Burns ${ }^{33}$ reported that there are very few clinicians proficient at comprehending and implementing graphic findings at the bedside. Despite pressure and flow scalars being the most traditional practice for analyzing patient-ventilator asynchrony, clinical application is not widespread. ${ }^{33}$ Such underuse is due to analysis complexity, limited ICU resources, and a lack of educational preparation. ${ }^{33}$ Moreover, such inexperience can lead to inadequate or excessive sedation, which can prolong hospital stay. ${ }^{33}$ Such sedation issues accompanied by complications from ventilator dependence contribute to a significant economic burden. ${ }^{34}$ Establishing collaboration between clinicians is imperative, and routine monitoring of graphics for patient-ventilator asynchronies in patients receiving mechanical ventilation can have significant contributions in the ICU environment. Ventilator graphic analysis is an integral component in the management of a mechanically ventilated patient, and clinicians must develop proper habits of evaluating these graphics to adjust the plan of care as needed.

\section{Scalars}

Clinicians responsible for ventilator setup and patient management must have a comprehensive understanding of the different ventilator scalar graphics, or waveforms, to recognize mechanical and clinical abnormalities. A pressure, volume, or flow waveform is known as a scalar graphic. ${ }^{35}$ Ventilator scalars allow the assessment of each variable over time. Innumerable changes can be detected in the scalars to facilitate the management of the mechanical ventilator. Clinicians can observe changes in a patient's condition, detect problems related to the ventilator system, evaluate the patient's response to interventions, assess lung mechanics, and use the information to adjust therapy as needed. ${ }^{35}$

Depending on the mode of ventilation, the shape of the flow-time scalar can either be set by the clinician or can depend on patient effort and respiratory mechanics. ${ }^{36}$ In the

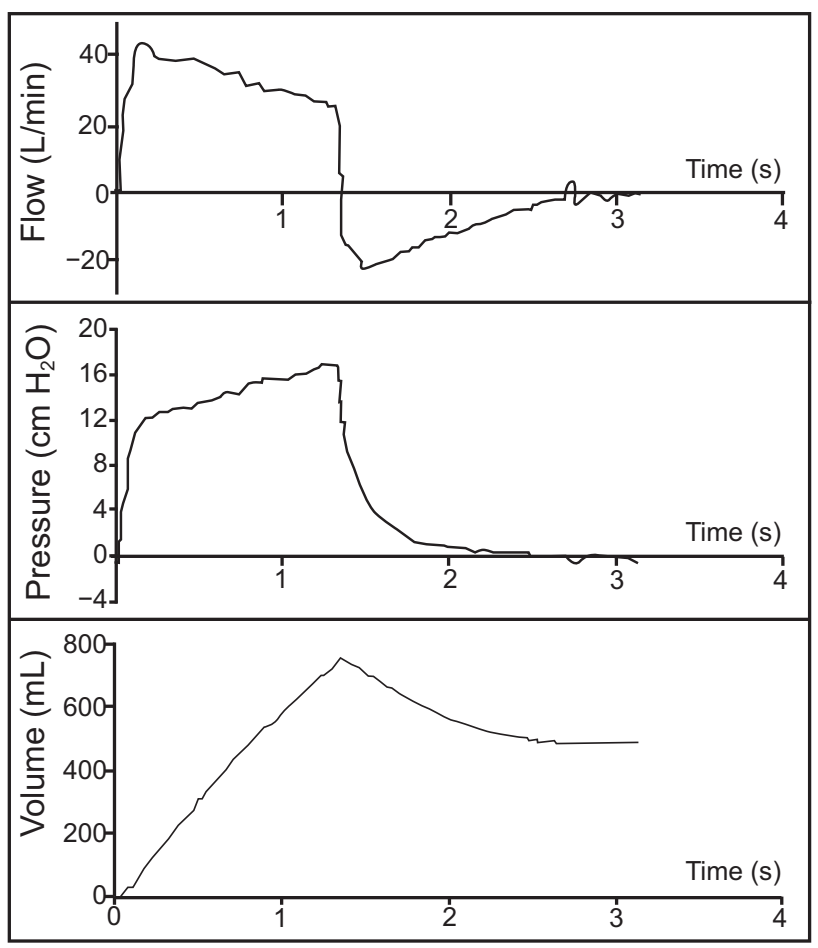

Fig. 4. Ventilator scalars indicating a leak. From Reference 38.

flow-time scalar, the expiratory flow pattern and the peak expiratory flow depend upon the changes in the patient's lung compliance and airway resistance, as well as the patient's active efforts. ${ }^{35}$ Flow-time scalars are crucial in recognizing clinically suspected airway obstruction, bronchodilator response, and air trapping (Fig. 3) ${ }^{35-37}$ Recognition of common abnormalities, such as a bronchospasm or accumulation of secretions, is obtained from a decreased peak expiratory flow or prolonged expiratory time. ${ }^{34,37}$ The presence of air trapping is detected if the expiratory flow curve does not return to zero and the following breath begins below baseline.

Information obtained from a volume-time scalar graph includes a visual illustration of the inspiratory $\mathrm{V}_{\mathrm{T}}$, inspiratory phase, expiratory phase, and inspiratory time. ${ }^{35}$ Although the volume-time scalar contains less useful information, it plays a role in the detection of a leak in the circuit or around the endotracheal tube. ${ }^{35-36}$ The presence of a leak is indicated when the expiratory volume tracing falls and then plateaus without reaching zero (Fig. 4). ${ }^{35,38}$ The volume of the leak can be estimated by measuring the distance from the plateau to baseline.

The pressure-time scalar is one of the most valuable waveforms in the clinical setting. It provides visual representation of PIP and PEEP. ${ }^{35}$ Although dynamic lung mechanics can be directly observed from a pressure-time scalar, the addition of an inflation hold also provides calculated static lung mechanics. Changes in the pressure-time scalar can have profound clinical importance because 3 of 


\section{VENTILATOR GRAPHICS}

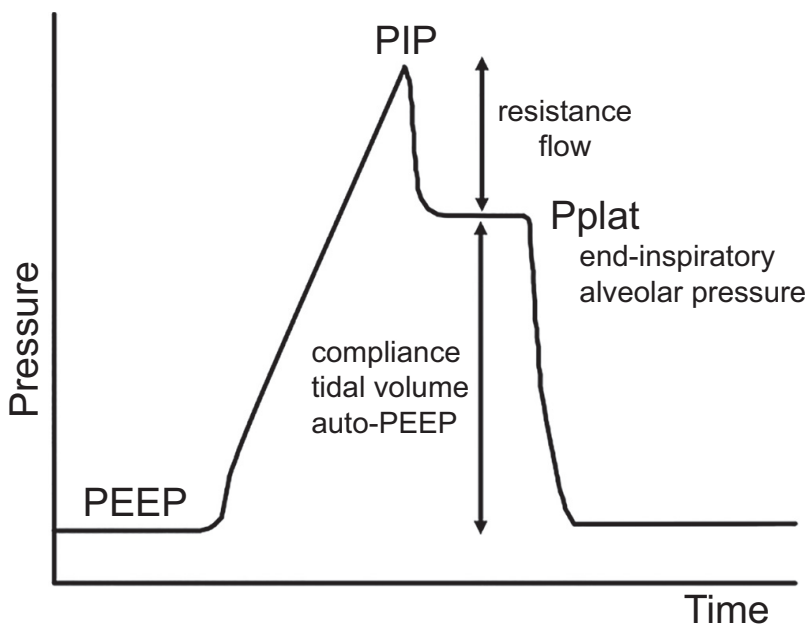

Fig. 5. Pressure-time scalar displaying increased transairway pressure, which is the difference between peak inspiratory pressure (PIP) and plateau pressure $\left(\mathrm{P}_{\text {plat }}\right)$.

the most common clinical situations are increased airway resistance, high inspiratory flow, and decreased lung compliance. ${ }^{35-36} \mathrm{~A}$ significant increase in the transairway pressure (ie, PIP - plateau pressure $\left[\mathrm{P}_{\text {plat }}\right]$ ) reflects an elevated airway resistance, whereas an increase in $\mathrm{P}_{\text {plat }}$ with a corresponding increase in PIP is consistent with decreased lung compliance (Fig. 5). ${ }^{35}$ Overall, ventilator scalars provide the information necessary to explain the physical interaction between ventilator and patient. Early interpretation and corrective measures are essential for optimum mechanical ventilation.

Stress Index. Since the ARDS Network trial of low $V_{T}$, clinical guidelines have recommended maintenance of $\mathrm{P}_{\text {plat }}$ at $<30 \mathrm{~cm} \mathrm{H}_{2} \mathrm{O}^{39-42}$ At the same time, laboratory studies began investigating an alternative ventilatory measurement that was thought to assist in selecting lung-protective settings. This measurement was based on the philosophy that during constant, relatively lower flow ventilation (ie, minimum of $0.8 \mathrm{~s}$ ), the rate of change in airway pressure paralleled the rate of change in respiratory system compliance. ${ }^{43-45}$ Therefore, a constant slope or straight line in the pressure-time scalar suggests no change in compliance during tidal ventilation. ${ }^{43,46}$ Comparatively, a progressive decrease in the slope indicates lung recruitment, whereas a progressive increase in the slope indicates hyperinflation. ${ }^{43,46}$ In an animal study in 2000 , Ranieri et $\mathrm{al}^{44}$ hypothesized that a straight shape pressure-time scalar could lessen the incidence of ventilator-induced lung injury. Anesthetized rats were randomly categorized into 1 of 3 groups with minimal stress, low-volume stress, or high-volume stress (Fig. 6). ${ }^{44,47}$ Animals in the minimal stress group were ventilated using lung-protective settings, and the PEEP was progressively increased until the shape

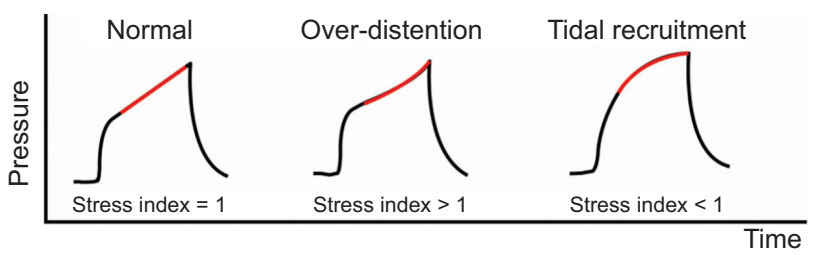

Fig. 6. Pressure-time scalars presenting various stress indices: minimal stress (stress index $=1$ ) indicates optimum (normal) ventilation; high-volume stress (stress index $>1$ ) specifies alveolar overdistention; low-volume stress (stress index $<1$ ) shows continuing recruitment. From Reference 47.

of the pressure-time scalar displayed a straight line. ${ }^{44}$ Animals in the low-volume stress group were ventilated on settings resulting in a pressure-time scalar showing a downward concavity, whereas animals in the high-volume stress group were ventilated on settings resulting in a pressuretime scalar showing an upward convexity. ${ }^{44,46}$ The main finding of the study determined that the shape of the pressure-time scalar helped identify injurious ventilation, defining this measurement as the stress index (normal range $=$ 0.9-1.1) ${ }^{44}$ In 2007, Grasso et al ${ }^{48}$ compared the ARDSNet ventilatory strategy to a PEEP-titration protocol based on the stress index. After the diagnosis of ARDS, subjects were initially ventilated for 12 hours according to the ARDSNet protocol, and for the subsequent 12 hours according a stress index protocol. ${ }^{39,48}$ The stress index protocol was identical to the ARDSNet protocol except that PEEP levels targeted a stress index in the normal range (ie, 0.9-1.1). ${ }^{44,45,48}$ Despite several limitations, including a small sample size, the authors reported that adjusting PEEP levels based on the stress index allowed for a greater reduction in the risk of alveolar hyperinflation in subjects with focal pattern ARDS, highlighting the importance of considering both irregular aeration loss and physiologic PEEP effects in ARDS management strategies. ${ }^{48}$ In 2013, Huang et $\mathrm{al}^{49}$ investigated the effects of PEEP titrated by stress index on lung-protective ventilation and lung recruitment. Following a recruitment maneuver, subjects with ARDS had their PEEP levels randomly titrated according to the stress index, an oxygenation protocol, static pulmonary compliance, or inflection points. ${ }^{49}$ Subjects titrated by the stress index had their PEEP levels determined with the pressure-time scalar, with optimum PEEP set between 0.9 and $1.1 \mathrm{~cm} \mathrm{H}_{2} \mathrm{O}$. PEEP titrated according to the oxygenation protocol involved a stepwise reduction approach consisting of PEEP decrements of $2 \mathrm{~cm} \mathrm{H}_{2} \mathrm{O}$ every 15 min. $^{49-50}$ For subjects randomized to the static pulmonary compliance group, PEEP was reduced in decrements of $2 \mathrm{~cm} \mathrm{H}_{2} \mathrm{O}$ until the lowest PEEP level providing maximum static pulmonary compliance was achieved. ${ }^{49}$ After identification of the lower inflection point with quasi-static P-V plots, PEEP was titrated in the last subject group according to the lower 

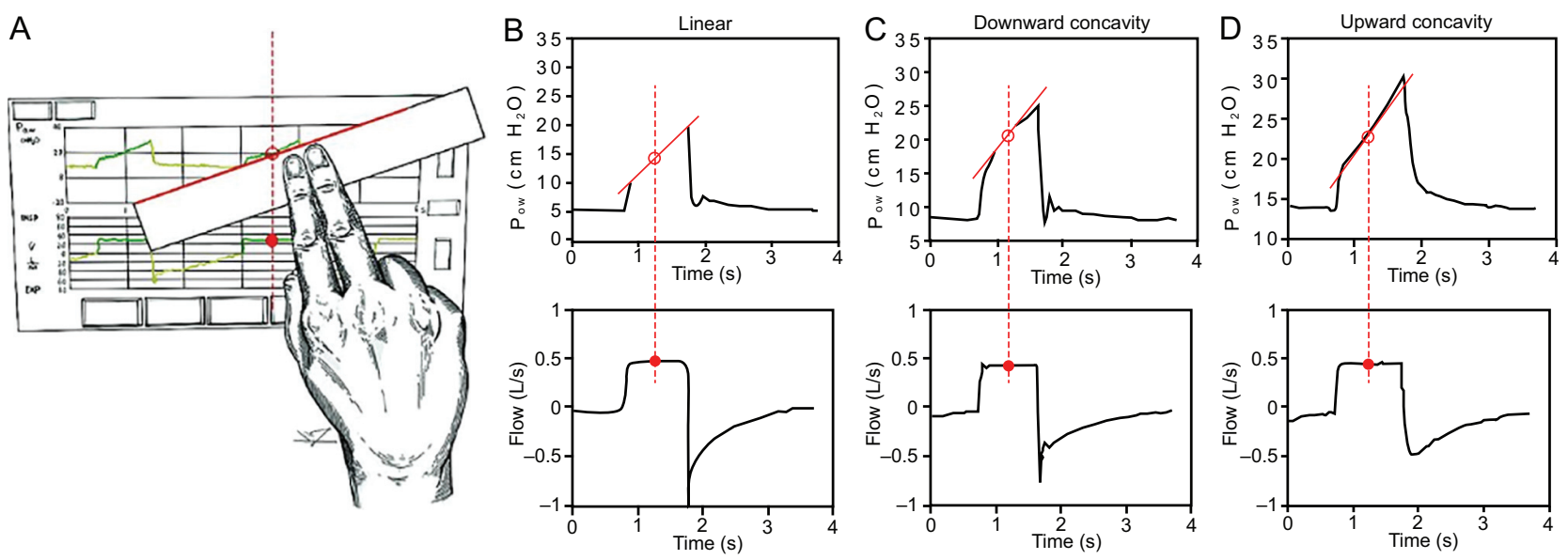

Fig. 7. Visual inspection of pressure-time scalar and stress index into 3 categories: a linear shape indicating optimum ventilation, a downward concavity showing alveolar overdistention, and an upward convexity denoting continued recruitment. $\mathrm{P}_{\mathrm{aw}}=$ airway pressure. From Reference 56 .

inflection point, determined as optimum PEEP $=$ lower inflection point $+2 \mathrm{~cm} \mathrm{H}_{2} \mathrm{O}$. There were several novel results, most important of which was PEEP titrated by the stress index was as effective in improving oxygenation as PEEP titrated according to the oxygenation protocol. Hence, PEEP titrated by stress index may be more beneficial and convenient for patients with pulmonary ARDS following a recruitment maneuver. In a study by Terragni et $\mathrm{al}^{51}{ }^{51}$ researchers assessed the diagnostic accuracy of $\mathrm{P}_{\text {plat }}$ and stress index to identify ventilator settings likely to produce injurious ventilation in subjects with ARDS. ${ }^{40}$ Phase 1 of the study consisted of assessing the precision of respiratory mechanics via computed tomography scans to identify the degree of overdistention. ${ }^{40,51,52}$ In phase 2, the impact of chest wall mechanics on injurious ventilation interpretation was examined. ${ }^{40,53}$ The key outcomes of the study were that a stress index $>1.05$ best identified subjects who were unprotected from injurious ventilation, and the authors claimed that the stress index was the best threshold for identifying injurious ventilation. ${ }^{40}$ Additionally, alterations in chest wall mechanics substantially impaired the ability of $\mathrm{P}_{\text {plat }}$ to estimate lung injury. Thus, the stress index more closely reflected the mechanical properties of the lung. Ferrando et $\mathrm{al}^{54}$ tested the hypothesis that adjusting $\mathrm{V}_{\mathrm{T}}$ to a safe stress index in an open-lung condition avoids hypoventilation while preventing overdistention, thus combining the concepts of low chest wall compliance and lung injury. This animal study was among the first to evaluate the stress index to guide $\mathrm{V}_{\mathrm{T}}$ and PEEP simultaneously, and it did so in a model of reduced chest wall compliance. The experimental protocol consisted of a recruitment maneuver immediately followed by a decremental PEEP titration to establish an open-lung PEEP level (ie, PEEP with best static respiratory system compliance). ${ }^{54-55}$ For $\mathrm{V}_{\mathrm{T}}$ adjustments, animals were randomized to either the $\mathrm{P}_{\text {plat }}$ group, where volumes were adjusted to maintain a target $\mathrm{P}_{\text {plat }}$ of
$30 \mathrm{~cm} \mathrm{H}_{2} \mathrm{O}$, or to the stress index group, where volumes were adjusted to maintain a stress index range (ie, 0.951.05). ${ }^{54}$ The key finding was that adjusting $\mathrm{V}_{\mathrm{T}}$ to a targeted, noninjurious stress index value in an open-lung model improves alveolar ventilation without increasing overdistention. The stress index appeared to be a useful alternative bedside tool for optimizing $\mathrm{V}_{\mathrm{T}}$ during lung-protective ventilation in situations of reduced chest wall compliance. Despite its clinical applicability, limitations of the stress index, including the need for dedicated instruments or specific ventilators, have encumbered its implementation in the ICU environment. In 2018, Sun et $\mathrm{al}^{56}$ published a study hypothesizing that the stress index could be reliably assessed by visual inspection of ventilator graphics. Using a standardized visual classification method, trained clinicians visually inspected and classified the shape of the pressure-time scalar for adult subjects receiving volume control ventilation in a constant flow pattern into 3 categories (upward convexity, linear, and downward concavity) (Fig. 7). ${ }^{56} \mathrm{~A}$ linear stress index was best in that it indicated no alveolar recruitment or overdistention, whereas an upward convexity indicated continuing recruitment and a downward concavity indicated alveolar overdistention. ${ }^{44,56}$ Simultaneously, quantitative analysis of the stress index, known as the reference method, was performed using dedicated instruments. ${ }^{56}$ The authors reported that visual inspection of the pressure-time scalar allowed for the accurate identification of the stress index, potentially helping clinicians recognize injurious ventilation in a timely manner at the bedside. ${ }^{56}$ Ultimately, it is apparent that respiratory system stress and strain caused by alveolar recruitment and collapse is a major mechanism of ventilator-induced lung injury. The stress index is a graphic tool that can be used to stabilize the lung on a breath-by-breath basis, allowing for optimum personalization of PEEP. 


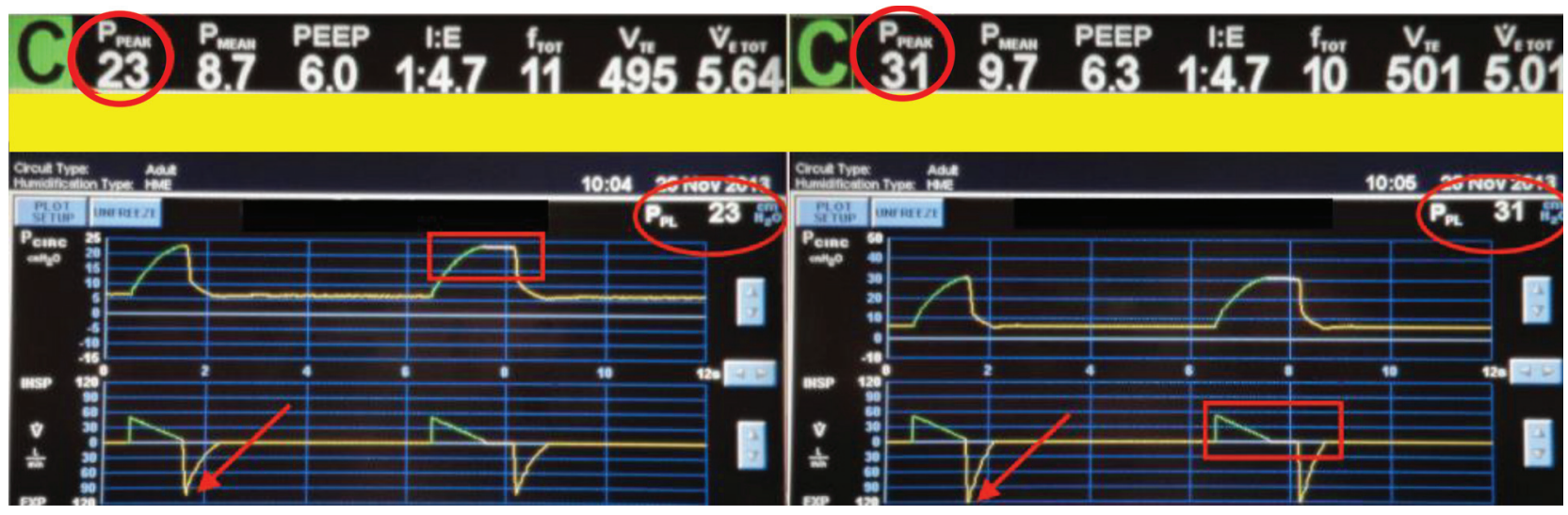

Fig. 8. VC-CMV ventilator graphics monitoring decreased lung compliance; there is no change in transairway pressure (i.e. $\left.\mathrm{PIP}-\mathrm{P}_{\text {plateau }}\right)\left(\mathrm{P}_{\mathrm{PEAK}}\right.$ = peak inspiratory pressure, $\mathrm{P}_{\mathrm{PL}}=$ plateau pressure) (red circles) and the peak expiratory flow rate increased $(\mathrm{V}=$ flow rate over time) (red arrows)

\section{Respiratory Mechanics}

The assessment of basic respiratory mechanics is crucial to monitoring ventilator graphics during mechanical ventilation. Assessing respiratory mechanics assists the clinician in adjusting ventilator settings, diagnosing lung conditions, and assessing the severity of lung impairment. At the bedside, changes to these mechanics can occur rapidly, meriting a speedy response, or they may happen as slow trends in pulmonary conditions, prompting adjustments to the care plan. This assessment requires the measurement of $\mathrm{V}_{\mathrm{T}}$, peak inspiratory flow, and 4 pressures: peak airway pressure, end-inspiratory $\mathrm{P}_{\text {plat }}$, end-expiratory pressure in the circuit, and, if intrinsic PEEP is suspected, endexpiratory pressure measured during an end-expiratory pause maneuver. Static measurements of respiratory mechanics rely on circuit occlusions, whereas dynamic measurements assess mechanical properties of the respiratory system continuously during mechanical ventilation. From these measured variables, the compliance and resistance of the respiratory system can be determined and are useful in the management of mechanically ventilated patients.

Compliance is the ratio of volume change per pressure change. Compliance is a measure of the elastic property of the respiratory system, including the lung and the chest wall. Measurement of compliance requires the use of an endinspiratory hold. Decreased compliance may occur in the case of ARDS, atelectasis, pneumothorax, lung fibrosis, or chest wall stiffness. ${ }^{47,57}$ An increase in compliance occurs in patients with obstructive lung disease. Monitoring compliance in patients with ARDS can provide useful information about the volume of aerated lung.

Abnormalities in compliance and resistance in patients are dependent on both the cause and severity of the disease. Figure 8 displays the effects of compliance on ventilator graphics. When evaluating transairway pressure, in the face of decreasing compliance, the peak pressure and $\mathrm{P}_{\text {plat }}$ will increase. Little to no change in transairway pressure is seen with changes in static compliance. Now observe the peak expiratory flow graphic: as compliance decreases, the peak expiratory flow increases. In contrast, as compliance increases, the peak expiratory flow decreases.

Respiratory system resistance during inspiration is the ratio of the difference between $\mathrm{P}_{\text {plat }}$ and PEEP to the rate of inspiratory flow. ${ }^{58}$ It describes the opposition to flow through the respiratory tract during inspiration, including frictional forces. Resistance is dependent on flow because the difference in PEEP and $\mathrm{P}_{\text {plat }}$ needed to overcome resistance increases disproportionately to changes in peak expiratory flow. Respiratory system resistance can only be accurately determined with a constant inspiratory flow pattern (ie, a square wave).$^{59}$ The level of resistance depends particularly on the diameter of the airways and whether air flow is laminar or turbulent. Turbulent flow is commonly present in large airways and major bifurcations, whereas laminar flow is present in the lower conducting airways. Increased resistance may occur in the case of COPD or asthma, a narrow endotracheal tube, excessive secretions, use of a heat and moisture exchanger, as well as incorrect positioning or kinking of the endotracheal tube. ${ }^{47,57}$

Figure 9 describes the effects of airway resistance on ventilator graphics. During the inspiratory phase, the increase in resistance gives rise to an increase in the difference between alveolar pressure and airway pressure. In the expiratory phase, the increase in airway resistance reduces the peak expiratory flow and increases the time needed for the respiratory system to reach functional residual capacity. Look again at the transairway pressure. The larger this difference, the larger the expected airway resistance. Observe the peak expiratory flow graphic: as resistance increases, the peak expiratory flow decreases. In contrast, as resistance decreases, the peak expiratory flow increases. Figure 


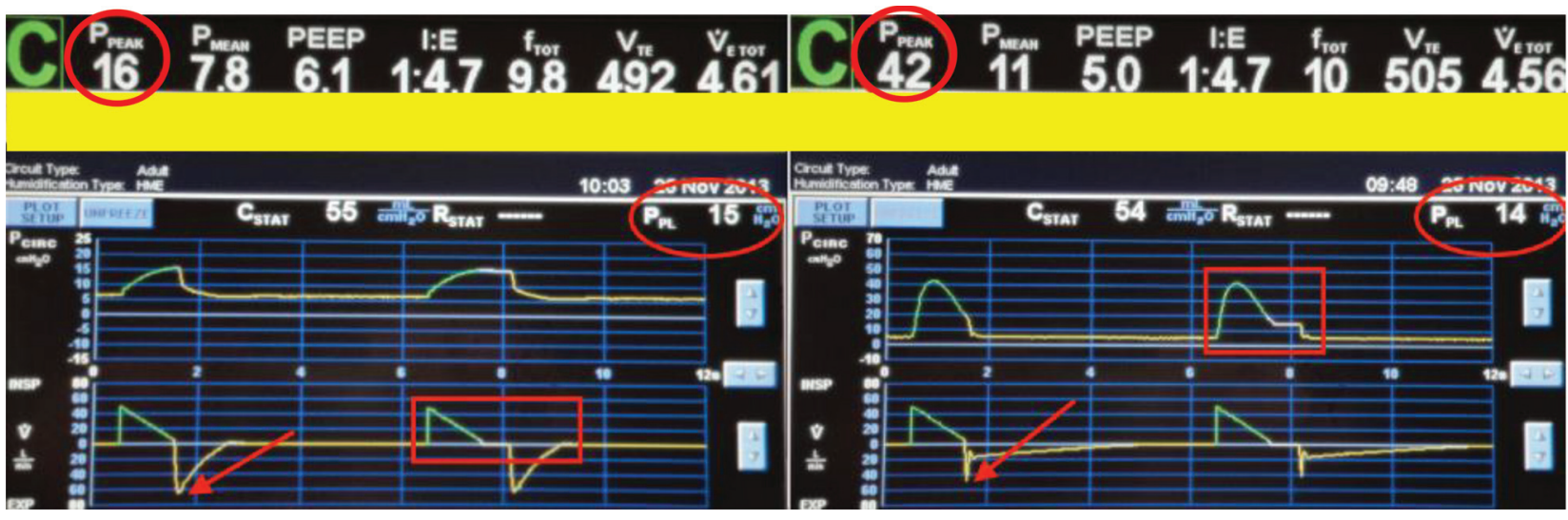

Fig. 9. VC-CMV ventilator graphics monitoring increased airway resistance; the larger the airway resistance, the larger the difference in the transairway pressure (i.e. PIP- $\left.P_{\text {plateau }}\right)\left(P_{\mathrm{PEAK}}=\right.$ peak inspiratory pressure, $\mathrm{P}_{\mathrm{PL}}=$ plateau pressure) (red circles). Also, as airway resistance increases, the peak expiratory flow rate decreases $(\mathrm{V}=$ flow rate over time) (red arrows)
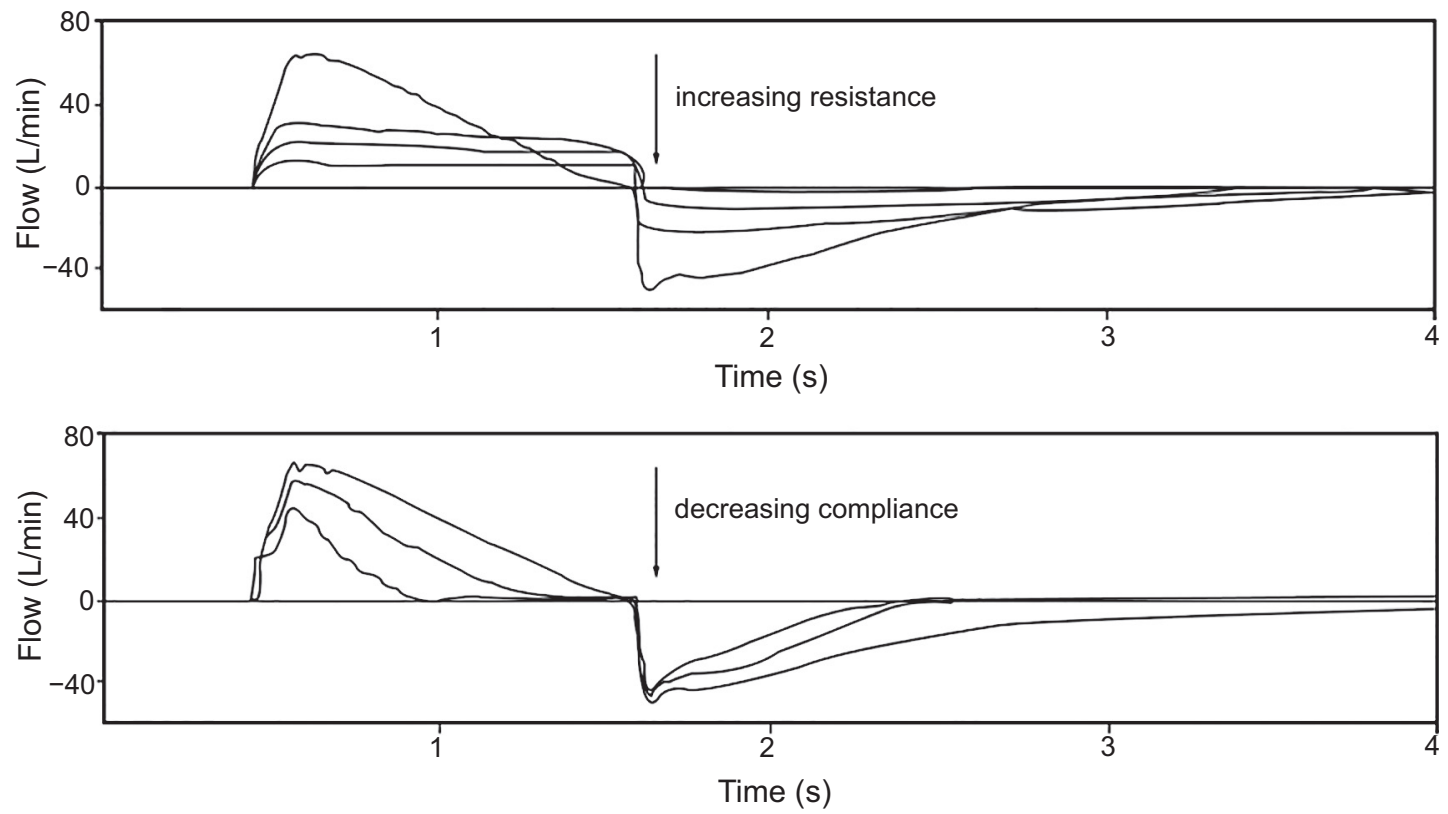

Fig. 10. Flow-time graphic variations of increased airway resistance and decreased compliance during pressure control continuous mandatory ventilation. From Reference 47.

10 illustrates flow-time graphic variations of increased resistance and decreased compliance during pressure control continuous mandatory ventilation. ${ }^{47}$ An increase in airway resistance leads to a decrease in both peak inspiratory and expiratory flow. ${ }^{47,60}$ Additionally, as airway resistance increases, the time required for flow equilibration $(\dot{\mathrm{V}}=0)$ increases while $\mathrm{V}_{\mathrm{T}}$ values decrease. ${ }^{47,60}$

\section{Plots}

Ventilator plots provide a 2-dimensional view of 2 variables plotted against each other. ${ }^{35}$ The static relationships can be used to analyze the properties of the respiratory system and help guide mechanical ventilation. ${ }^{61}$ The flow-volume plot provides information regarding peak inspiratory flow, peak expiratory flow, and $\mathrm{V}_{\mathrm{T}} \cdot{ }^{35} \mathrm{With}$ regard to abnormalities, when the expiratory volume on a flow-volume plot does not return to zero, the deficit of volume indicates the magnitude of an air leak (Fig. 11). ${ }^{38}$ The typical pattern of increased airway resistance is reflected on a flow-volume plot as a decreased peak expiratory flow and a scooped out pattern on the expiratory tracing (Fig. 12). ${ }^{37}$ Flow-volume plots have also been used as diagnostic markers. Flow-volume plots have the ability to document the presence and 


\section{VENTILATOR GRAPHICS}

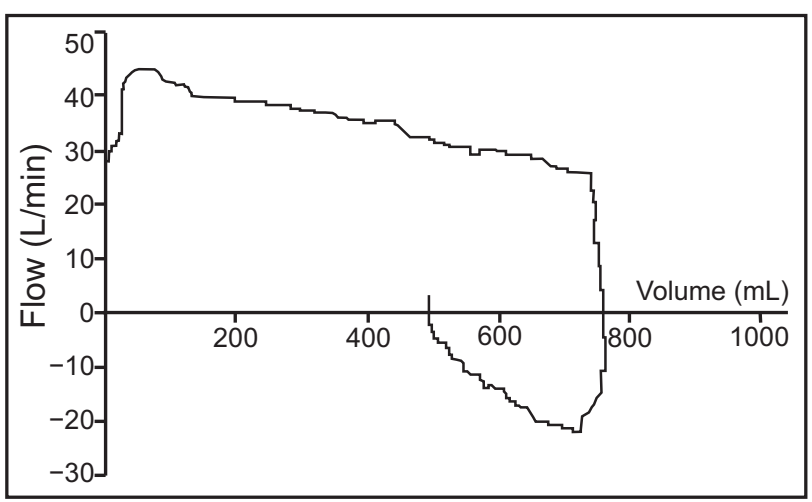

Fig. 11. An air leak on a flow-volume plot (lower panel). From Reference 38.

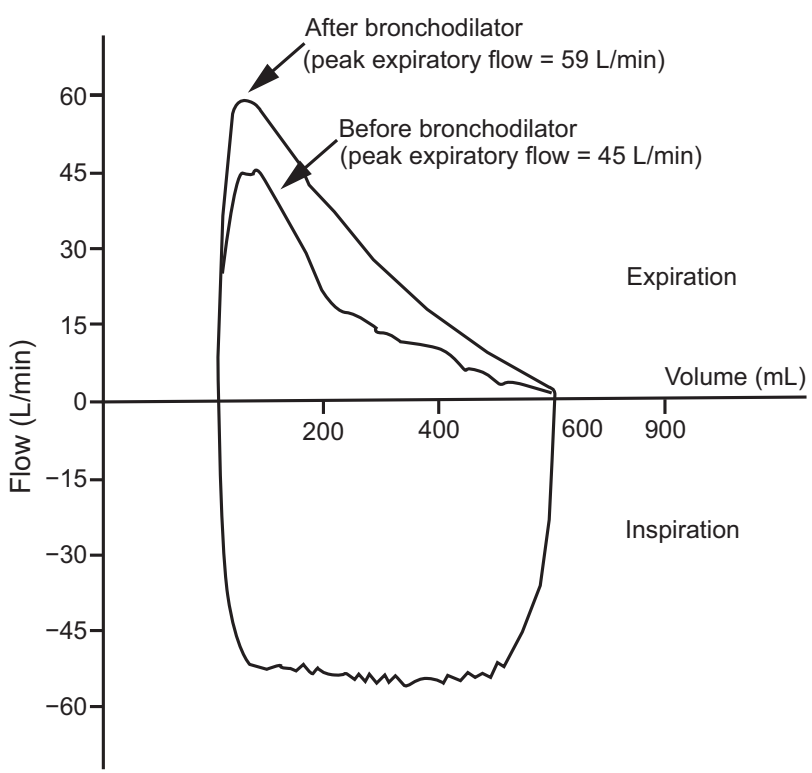

Fig. 12. A flow-volume plot showing increased airway resistance. From Reference 37.

severity of airway obstruction. Weiner et $\mathrm{al}^{62}$ reported in 2016 that abnormal flow-volume plots were reproducible and could be used as a metric to measure disease severity. Karkhanis et $\mathrm{al}^{63}$ noted in 2013 that observation of ventilator flow-volume plots remains the most effective way of detecting upper airway obstruction, even before the manifestation of symptoms.

A P-V plot traces changes in pressures and corresponding changes in volume. $\mathrm{P}-\mathrm{V}$ plots usually have a sigmoidal shape. PIP and delivered $V_{T}$ can readily be obtained from the $\mathrm{P}-\mathrm{V}$ plot. ${ }^{35} \mathrm{~A}$ few of the common abnormalities seen in $\mathrm{P}-\mathrm{V}$ plots include changes in airway resistance (ie, associated with an abnormal widening of the P-V plot, which is known as increased hysteresis); the classic sign of alveolar overdistention, known as beak effect or duckbill, showing an increase in airway pressure without an appreciable

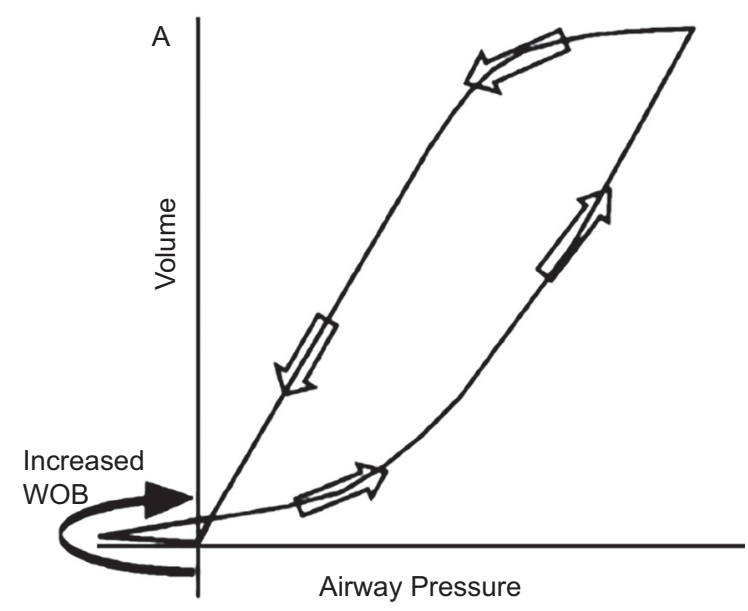

Fig. 13. A pressure-volume plot indicating increased patient effort or work of breathing. From Reference 37.

increase in volume; and a significant clockwise deflection prior to the initiation of a breath, indicating increased patient effort (Fig. 13). ${ }^{35,37}$

Amato et $\mathrm{al}^{64}$ popularized the $\mathrm{P}-\mathrm{V}$ plot approach for setting PEEP and identified lower and upper inflection points. Shortly thereafter, Lu and Rouby ${ }^{65}$ reported that, despite the enthusiastic use of inflection points, there was no magic number that defined the risk of overdistention. In each patient, the upper inflection point varies, and thus routine measurements of $\mathrm{P}-\mathrm{V}$ plots remained a critical element for implementing lung protective ventilation (LPV). ${ }^{65}$ In 2003, Rouby et al ${ }^{66}$ described the relationship between lung morphology and P-V plots, stating that in subjects with ARDS with diffuse loss of aeration, the P-V plot is basically a lung recruitment curve and does not reflect the lung mechanics of the baby lung. However, the analysis of P-V plots is much more complex in patients with ARDS with a focal loss of aeration because it is influenced by the mechanical properties of the remaining aerated lung and by the recruitment of the nonaerated lung. ${ }^{66}$ Therefore, keeping the $\mathrm{P}_{\text {plat }}$ below the upper inflection point for the majority of patients with ARDS is not an absolute guarantee against lung overdistention.

Today, the 3 most common methods used to measure P$\mathrm{V}$ plots are the use of a supersyringe, inflation with a constant slow flow (ie, the constant-flow method), and $\mathrm{P}_{\text {plat }}$ measurements at various inflation volumes (ie, the multiple-occlusion method). ${ }^{67-68}$ The supersyringe method involves the use of a large syringe with up to $2 \mathrm{~L}$ of volume. During inflation and deflation, volumes and the resulting pressures are recorded in a stepwise fashion. ${ }^{67-68}$ These recordings are plotted against the correlating static pressure points to obtain the plot. Additional equipment needs, disconnection of the patient from the ventilator, and the requirement of patient paralysis are all disadvantages of the supersyringe method. The constant-flow method is 


\section{VENTILATOR GRAPHICS}

available on particular ventilators and involves the use of very low inspiratory $(<10 \mathrm{~L} / \mathrm{min})$ and expiratory flow. Drawbacks to this method include the fact that some ventilators cannot control expiratory flow, and additional sedation is required to eliminate any spontaneous respiratory efforts. ${ }^{67-68}$ The multiple-occlusion method is also performed using ventilators by causing intermittent interruptions of tidal breathing at various inflation volumes to obtain each $\mathrm{P}-\mathrm{V}$ data point. ${ }^{67-68}$ The advantages of this method are that both the inflation and deflation plots are obtained, and there is no disconnection from the ventilator. ${ }^{67-68}$ Sedation or paralysis may still be required, however, to inhibit spontaneous respiratory efforts.

In 2009, Piacentini et $\mathrm{al}^{69}$ compared new automated methods to traditional methods for measuring P-V plots in subjects with acute lung injury. $\mathrm{P}-\mathrm{V}$ plots were obtained for each subject using the traditional CPAP technique and an automated software program on a modern ventilator. ${ }^{69}$ Results indicated that the automated bedside tool was a valid alternative for tracing $\mathrm{P}-\mathrm{V}$ plots and avoided the drawbacks of other techniques. ${ }^{69}$ Although the modern software requires no additional training or equipment, there are still limitations to its use.

Inflection Points. As previously stated, one approach for setting PEEP is based on P-V plot inflection points. Starting compliance refers to the relatively low volume change when inflation begins below functional residual capacity as transpulmonary pressure increases. ${ }^{70}$ Starting compliance mirrors the relatively small area of aerated lung or the relatively high pressure needed to overcome airway closures. ${ }^{70-71}$ The starting compliance portion of the P-V plot is followed by a rapid change with a concave appearance; this is termed the lower inflection point. ${ }^{72}$ The lower inflection point indicates a rapid reopening of collapsed peripheral airways and alveoli. ${ }^{61}$ Above the lower inflection point, the P-V plot becomes linear and is known as the inflation compliance. ${ }^{73}$ As total lung capacity is approached, compliance decreases and the P-V plot becomes convex, and this is termed end compliance. ${ }^{73}$ This change in distensibility at maximum inflation is termed the upper inflection point. ${ }^{73}$

Despite enthusiasm for the use of P-V plots and inflection points in ventilator management, there are a number of issues that prevent the routine use of these methods. A few of these issues include the requirement for sedation, and oftentimes paralysis, to obtain an accurate measurement, the need for mathematical curve fitting to identify precise inflection points, and the necessity to disregard inhomogeneity within diseased lungs. ${ }^{47,67,74}$ Furthermore, the inflation limb of the P-V plot is generally measured when in fact the deflation limb might provide more useful information for setting PEEP levels. ${ }^{47,67}$ Esophageal manometry may also be necessary to separate the lung from the chest wall, which could affect the shape of the P-V plot. ${ }^{47,67}$ In light of these issues, the best strategy for setting PEEP and $\mathrm{V}_{\mathrm{T}}$ remains controversial. In 2016, Kallet ${ }^{75}$ published a pro/ con argument around the question of whether PEEP titration should be based on P-V plots. In the pro argument, he stated that 2 randomized controlled trials demonstrated significant reduction in mortality and duration of mechanical ventilation using open-lung ventilation based on $\mathrm{P}-\mathrm{V}$ plots. The evidence indicated that the inflammatory cascade in ARDS was reduced when ventilation was based on information provided by the inflation P-V plot. Conversely, his con argument stated that, despite original thoughts regarding the use of the P-V plot, data showed that PEEP requirements determined from the lower inflection point were higher than those actually needed to maximize compliance during lung-protective ventilation. ${ }^{75}$ Further investigation of the P-V plot generated uncertainties that dampened its enthusiasm. Although ventilator plots and inflection point measurements are important for assessing disease status as well as for selecting suitable ventilator parameters, several key questions remain unanswered. Limitations to these techniques must be overcome, and simplified respiratory monitoring procedures need to be considered to diminish the effects of ventilator-induced lung injury.

Work of Breathing. WOB is defined as the energy required during each respiratory cycle. WOB is generally the area on a pressure-volume diagram, and is expressed in joules $(\mathrm{J}): \mathrm{WOB}=\int(\mathrm{P} \times \mathrm{V}){ }^{76}$ Joules/liter $(\mathrm{J} / \mathrm{L})$ more commonly defines the work per respiratory cycle divided by the $\mathrm{V}_{\mathrm{T}}{ }^{76}$ Measuring WOB is a useful approach to calculate the energy required as ventilation begins. ${ }^{76}$ The WOB measurement is an important monitor of a patient's respiratory status, lung reserve, and probability of weaning success from mechanical ventilation. The dynamic relationship between pleural pressure and lung volume during breathing describes what is known as the Campbell diagram. ${ }^{76}$ The Campbell diagram and WOB parameter can be used as reference values for subsequent calculations when a patient develops spontaneous efforts. As discussed by multiple authors, WOB measurements are extremely useful in mechanical ventilation because they contribute to important progress in patient management as well as further comprehension and optimization of several ventilator settings and graphics. ${ }^{11,76}$ Studies on WOB have yielded great insight into the pathophysiology of weaning failure and have contributed to the advancements made in noninvasive ventilation (NIV) management. ${ }^{76}$ Additionally, research has shown that the WOB calculation complements the prediction of weaning outcomes provided by the rapid shallow breathing index (RSBI) parameter. ${ }^{11}$ However, despite being a useful clinical evaluation tool, indirect WOB measurement can be misleading. Some patients may appear to have excessive WOB but are in fact quite comfortable, whereas others may appear to be relaxed at their current level 


\section{VENTILATOR GRAPHICS}

of ventilatory support but cannot tolerate any further increase in their WOB. The use of direct bedside monitors has been proposed to better assess WOB and to monitor spontaneous efforts more closely while fine-tuning the level of ventilatory support. ${ }^{77-78}$ Through the use of an esophageal balloon, intrapleural pressure measurements can be estimated and WOB can be calculated by integration of the P-V plot. ${ }^{77-78}$ WOB techniques have been recommended to accurately adjust ventilation settings, optimize gas exchange, and minimize unwarranted patient exertion. ${ }^{77-78}$ Despite multiple methods to quantify spontaneous breathing efforts, no study has documented the most useful monitoring parameters or which modifications to ventilator management resulted in the best outcomes. ${ }^{77-78}$

\section{Asynchronies}

The analysis of ventilator graphics in NIV can be useful in the optimization of patient-ventilator interactions. In a randomized controlled study, Di Marco et $\mathrm{al}^{79}$ compared graphic analysis to standard numerical data analysis to determine the efficacy of patient care during NIV. Results indicated that graphic analysis was associated with a higher rate of $\mathrm{pH}$ normalization and that graphic analysis may have a more positive effect on physiological and patientcentered outcomes. ${ }^{79}$ In another study, Longhini et $\mathrm{al}^{80}$ assessed the ability of clinicians to identify asynchronies during NIV through ventilator graphic analysis. There were 3 major findings from this study: the overall ability of clinicians to identify patient-ventilator asynchronies during NIV by graphic analysis was low, the experience and expertise of the clinicians did not affect the rate of patient-ventilator asynchrony detection, and the rate of proper detection was inversely related to the prevalence of asynchrony. These results regarding asynchrony detection via graphic analysis are in direct contrast to other invasive mechanical ventilation studies. ${ }^{80}$ The authors suggested that 6 months of training may be sufficient to reach a plateau in the graphic analysis learning curve; on the other hand, it was possible that detection of asynchronies during NIV is extremely problematic, regardless of the level of experience. ${ }^{80}$

Evaluation using graphic analysis is not only a noninvasive and reliable alternative method, but it also has shown good correlation with invasive methods of mechanical ventilation. Ramirez et $\mathrm{al}^{81}$ assessed the ability of ICU clinicians to identify different types of asynchronies according to their years of experience, profession, and prior training in mechanical ventilation using graphic analysis. This observational study had 2 findings: the number of trained clinicians (ie, those who completed at least one course in mechanical ventilation from a formal educational institution) who identified 3 asynchronies was significantly higher than clinicians in the group without such training, and trained clinicians who had previous training in

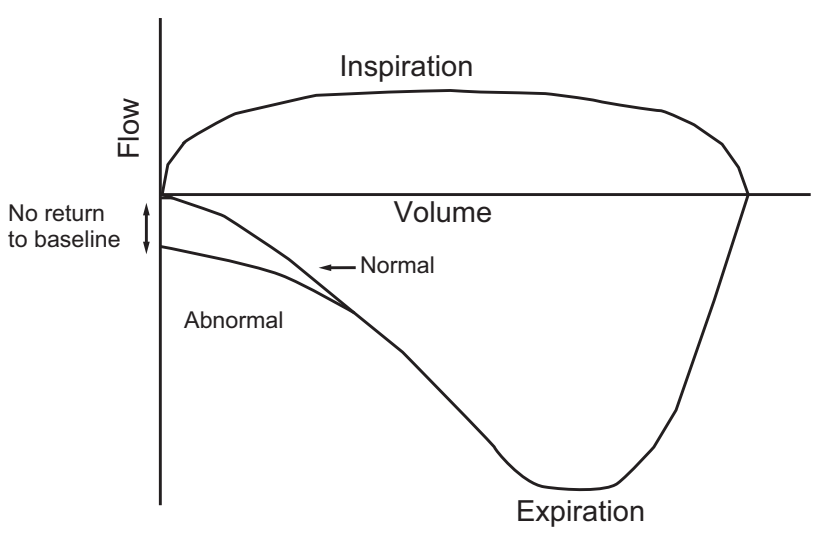

Fig. 14. A flow-volume (F/N) plot identifying air trapping. From Reference 37.

mechanical ventilation increased their odds of identifying asynchronies correctly nearly 4 -fold. ${ }^{81}$ This study revealed that identifying and interpreting asynchrony is not easy, even for experienced clinicians; $<40 \%$ of clinicians were able to correctly identify all 3 types of asynchronies. ${ }^{81}$ Formal training in mechanical ventilation is significantly associated with the ability of clinicians to identify asynchronies using graphic analysis; in addition, neither experience nor profession was shown to be associated with the ability of clinicians to identify asynchrony correctly using graphic analysis. ${ }^{81}$ Colombo et $\mathrm{al}^{31}$ aimed to assess the ability of ICU clinicians to detect patient-ventilator asynchrony during pressure support ventilation and to determine the impact of expertise on the ability to recognize asynchronies. Experienced ICU clinicians were able to detect less than one third of all asynchronies, indicating that the ability to properly recognize patient-ventilator asynchrony by visual inspection of ventilator graphics was overall quite low and was influenced only moderately by clinical expertise.

Clearly, when clinicians truly understand and recognize the shapes of ventilator graphics, they can use that knowledge as a noninvasive bedside tool to monitor patient response to ventilatory support. They can, in the simplest terms, recognize trouble. Figure 14 shows a flow-volume plot that identifies air trapping. On a flow-volume plot, air trapping may be the culprit if the expiratory curve doesn't return to the starting point to complete the loop. Figure 15 shows ventilator graphics identifying excessive trigger threshold assynchrony. ${ }^{37}$ These graphics show ineffective patient efforts during both inspiration and expiration.

\section{Ventilator Graphics: The Future}

So, what does the future hold for ventilator graphics? The glaring problem most commonly discussed is that ICU clinicians are grossly unskilled at understanding, utilizing, and interpreting ventilator graphics and fixing the associated 


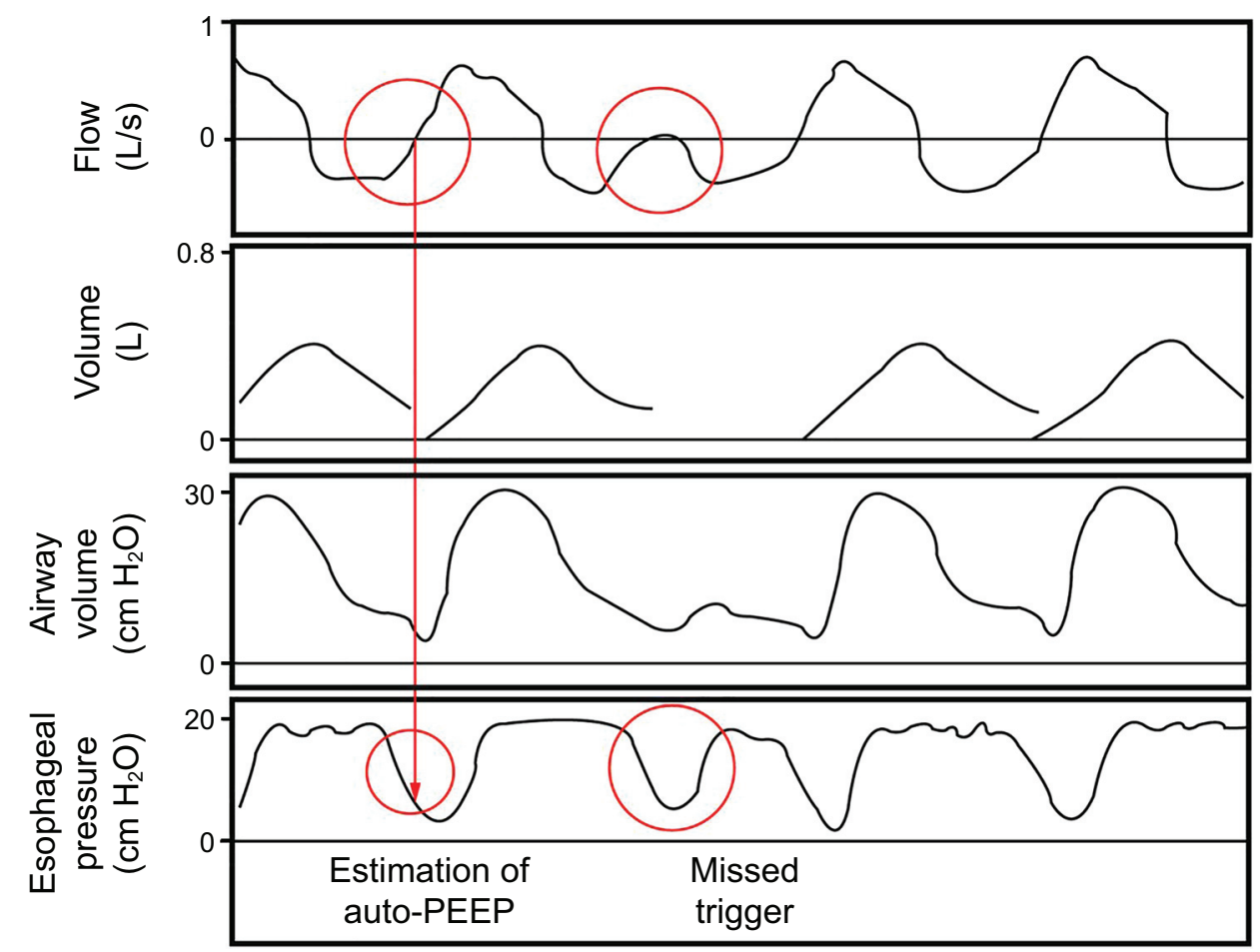

Fig. 15. Ventilator scalars illustrating excessive triggering threshold, which causes increased word of breathing. Esophageal pressure waveforms pick up ineffective efforts during inspiration and expiration. From Reference 37.

patient-ventilator asynchronies that occur during mechanical ventilation. Research indicates that there is a significant gap in knowledge when it comes to interpretation of ventilator graphics, and this is a problem for several reasons. How will we fix it? If technology has truly surpassed clinicians' ability to utilize this information at the bedside, does that mean we ultimately rely on automation to interpret these issues and resolve the problems? There is quite a bit of literature discussing concepts such as automated detection of patient-ventilator asynchrony through graphic analysis, continuous trend analysis, and improved synchrony modes. Can such promising systems help clinicians expand their knowledge about patient-ventilator interaction and further advance mechanical ventilation?

Gutierrez et $\mathrm{al}^{82}$ compared an automatic, noninvasive method for patient-ventilator asynchrony monitoring to the asynchrony index. In this observational study, automated spectral analysis consisted of digitally sampling airway flow frequency and pressure signals continuously for $2 \mathrm{~h}$, whereas the asynchrony index values were visually measured from the flow and pressure tracings on the ventilator every 30 min. ${ }^{82}$ Their results indicated that spectral analysis of airway flow provided a prompt recognition of ventilator asynchrony and was easily adaptable to existing monitoring systems. ${ }^{82} \mathrm{In}$ 2013, Sinderby et al $^{83}$ introduced an automated, objective, standardized method to rapidly display patient-ventilator interaction at the bedside. Through manual and automated re-analysis of data acquired from previously mechanically subjects, patient-ventilator interactions were evaluated by comparing $\mathrm{EA}_{\mathrm{di}}$ waveforms and ventilator pressures. ${ }^{83}$ Manual and automated algorithms detected the timing of the $\mathrm{EA}_{\mathrm{di}}$ as well as the ventilator pressure waveform for each respiratory cycle and quantified the error between them; the authors called this the NeuroSync Index. ${ }^{83}$ The comparison resulted in high interrater reliability scores and increased sensitivity to the automated algorithm in detecting ventilator asynchrony. ${ }^{83}$

The continued development of innovative technologies, such as automatic detection methods, could improve the identification of asynchrony, rapidly notify clinicians, and possibly be used as the basis for automated adjustment of ventilator settings. Another clinical need is continuous realtime graphic analysis. Clinicians cannot always be at the bedside, so technology that mimics such capabilities is needed to rapidly detect changes in a patient's condition. Ideally, new technology would continuously analyze ventilator graphics, identify any patient respiratory activity, and instantaneously trigger according to the patient's effort. Although the importance of knowing a patient's present respiratory status cannot be overemphasized, continuous graphic trend analysis could allow the clinician to make more informed decisions regarding patient care. The use of histograms, or overlapping ventilator or hemodynamic information, is the way of the future. The innovative concept of 


\section{VENTILATOR GRAPHICS}

closed-loop control systems allows for the automatic adjustment of ventilation and oxygenation parameters. In 2013, Clavieras et al ${ }^{84}$ compared gas exchange and breathing pattern variability between a closed-loop control mode, Intellivent, and pressure support ventilation. Ventilatory parameters and $\mathrm{P}_{\mathrm{aO}_{2}} / \mathrm{F}_{\mathrm{IO}_{2}}$ ratios were recorded continuously for 2 periods of $24 \mathrm{~h} \cdot{ }^{84}$ Results showed that there were significant improvements in $\mathrm{P}_{\mathrm{aO}} / \mathrm{F}_{\mathrm{IO}_{2}}$ after $24 \mathrm{~h}$ on Intellivent, whereas there was no change on pressure support ventilation. In addition, there were significantly more adjustments made to inspiratory pressure, PEEP, and $\mathrm{F}_{\mathrm{IO}_{2}}$ settings on Intellivent than on pressure support ventilation. ${ }^{84}$ Intellivent improved oxygenation, ventilatory parameters, and time spent in an adequate ventilation zone compared to pressure support ventilation. Such outcomes warrant further investigation into the clinical impact of closed-loop control versus conventional modes of mechanical ventilation.

There are several other new feedback modes of mechanical ventilation that respond to patient-based requirements, thus improving outcomes. Dual-control modes have gained popularity because of the advantageous combination of concepts from volume control ventilation and pressure control ventilation. Dual-control modes allow for a set volume target with pressure-controlled breaths, thus allowing for a wide variety of pressure, flow, and volume graphics. ${ }^{85}$ Other newer, nonconventional modes including adaptive support ventilation, proportional assist ventilation, airway pressure release ventilation, neurally adjusted ventilatory assist, and Smartcare have been shown to improve patientventilator asynchrony, decrease mechanical ventilation duration, and enhance patient safety. ${ }^{86}$ Although working principles may help outline patient-based ventilatory strategies, clinical limitations require further exploration, long-term studies are needed to prove effectiveness of new modes. Such tools could help clinicians increase their knowledge patient-ventilator interaction and further improve mechanical ventilation management. Ventilator graphics are critical to understanding mechanical ventilation and patient-ventilator interaction, and they must become an integral part of clinical training and research moving forward.

\section{Conclusions}

Ventilator graphics continue to be integral components in the management of critically ill patients. Ventilator graphics are widely available and are a valuable bedside monitoring tool that provide instant information about patient-ventilator interaction and device function. Bedside lung mechanics remain beneficial aids to clinical decision making in the ICU environment. In addition, secondary measures such as stress index, inflection points, and WOB may help optimize mechanical ventilation management and prevent injurious ventilation. Although mechanical ventilation technology continues to progress, such advancements do not always equate to optimized patient care. Rather, understanding the complex patient-ventilator interface should be considered the most critical component of the overall ICU assessment. A stepwise approach can lead to better understanding and a more consistent interpretation of ventilator graphics. Interpretation strategies aimed at reducing patient-ventilator asynchrony may improve outcomes and costs associated with mechanical ventilation. Clinicians must understand the usefulness of these graphics and be able to identify and respond to problems promptly and appropriately. By understanding how to interpret and apply ventilator graphics, clinicians can enhance the effectiveness of mechanical ventilation and optimize patient care. Ventilator graphics literature and education must continue to evolve to address effective and cost-efficient mechanical ventilation management practices.

\section{REFERENCES}

1. Rose L. Management of critically ill patients receiving noninvasive and invasive mechanical ventilation in the emergency department. Open Access Emerg Med 2012;4:5-15.

2. Hess DR. Applied respiratory physiology: use of ventilator waveforms and mechanics in the management of critically ill patients (forward). Respir Care 2005;50(1):26-27.

3. Durbin CG. Applied respiratory physiology: use of ventilator waveforms and mechanics in the management of critically ill patients. Respir Care 2005;50(2):287-293.

4. Nilsestuen JO, Hargett KD. Using ventilator graphics to identify patient-ventilator asynchrony. Respir Care 2005;50(2):202-234.

5. Chatburn RL. Simulation studies for device evaluation. Respir Care 2014;59(4):e61-e66.

6. Arnal JM, Garnero A, Saoli M, Chatburn RL. Parameters for simulation of adult subjects during mechanical ventilation. Respir Care 2018;63(2):158-168.

7. Henderson WR, Chen L, Amato MB, Brochard LJ. Fifty years of research in ARDS: respiratory mechanics in acute respiratory distress syndrome. Am J Respir Crit Care Med 2017;196(7):822-833.

8. Primiano FP Jr, Chatburn RL. Zen and the art of nomenclature maintenance: a revised approach to respiratory symbols and terminology. Respir Care 2006;51(12):1458-1470.

9. Chatburn RL. Classification of mechanical ventilators. Respir Care 1992;37(9):1009-1025.

10. Lucangelo U, Bernabè F, Blanch L. Lung mechanics at the bedside: make it simple. Curr Opin Crit Care 2007;13(1):64-72.

11. Brochard L, Martin GS, Blanch L, Pelosi P, Belda FJ, Jubran A, et al. Clinical review: respiratory monitoring in the ICU - a consensus of 16 . Crit Care 2012;16(2):219.

12. Mott-Smith M. Newton's Third Law of Motion. Am J Phys 1944;12 (2):109-109.

13. Holanda MA, Vasconcelos RDS, Ferreira JC, Pinheiro BV. Patientventilator asynchrony. J Bras Pneumol 2018;44(4):321-333. Erratum in: J Bras Pneumol 2018;44(4):339.

14. Gilstrap D, Macintyre N. Patient-ventilator interactions: implications for clinical management. Am J Respir Crit Care Med 2013;188 (9):1058-1068.

15. Pham T, Brochard LJ, Slutsky AS. Mechanical ventilation: state of the art. Mayo Clin Proc 2017;92(9):1382-1400.

16. Thille AW, Rodriguez P, Cabello B, Lellouche F, Brochard L. Patientventilator asynchrony during assisted mechanical ventilation. Intensive Care Med 2006;32(10):1515-1522. 


\section{VENTILATOR GRAPHICS}

17. Slutsky AS. History of mechanical ventilation: from Vesalius to ventilator-induced lung injury. Am J Respir Crit Care Med 2015;191 (10):1106-1115.

18. Kacmarek RM. The mechanical ventilator: past, present, future. Respir Care 2011;56(8):1170-1180.

19. Dellaca RL, Veneroni C, Farre R. Trends in mechanical ventilation: are we ventilating our patients in the best possible way? Breathe (Sheff) 2017;13(2):84-98.

20. Sanborn WG. Monitoring respiratory mechanics during mechanical ventilation: where do the signals come from? Respir Care 2005;50 (1):28-52.

21. Thille AW, Lyazidi A, Richard JC, Galia F, Brochard L. A bench study of intensive-care-unit ventilators: new versus old and turbinebased versus compressed gas-based ventilators. Intensive Care Med 2009;35(8):1368-1376.

22. Marjanovic NS, De Simone A, Jegou G, L'Her E. A new global and comprehensive model for ICU ventilator performances evaluation. Ann Intensive Care 2017;7(1):68.

23. Govoni L, Dellaca' RL, Peñuelas O, Bellani G, Artigas A, Ferrer M, et al. Actual performance of mechanical ventilators in ICU: a multicentric quality control study. Med Devices (Auckl) 2012;5:111-119.

24. Garnier M, Quesnel C, Fulgencio JP, Degrain M, Carteaux G, Bonnet $\mathrm{F}$, et al. Multifaceted bench comparative evaluation of latest intensive care unit ventilators. Br J Anaesth 2015;115(1):89-98

25. Delgado C, Romero JE, Puig J, Izquierdo A, Ferrando C, Belda FJ, Soro M. Performance of the new turbine mid-level critical care ventilators. Respir Care 2017;62(1):34-41.

26. Chatburn RL. Fundamentals of mechanical ventilation. Cleveland Heights: Mandu Press Ltd; 2003.

27. Dhaliwal MS, Raghunathan V, Sharma J. Ventilator graphics: a step wise approach and clinical application. J Pediatr Crit Care 2015;2 (1):67-84

28. Prielipp RC, Lewis K, Morell RC. Ventilator failure in the ICU: déjà vu all over again. APSF Newsletter 1998;13(3)

29. Krishna Kumar BR, Ravi M, Dinesh K, Nanda A. Ventilator malfunction. J Anaesthesiol Clin Pharmacol 2011;27(4):576.

30. Sripriya R, Parthasarathy S, Ravishankar M. Ventilator dysfunction: role of graphics in detection. Ain-Shams J Anaesthesiol 2016;9 (3):465-467.

31. Colombo D, Cammarota G, Alemani M, Carenzo L, Barra FL, Vaschetto R, et al. Efficacy of ventilator waveforms observation in detecting patient-ventilator asynchrony. Crit Care Med 2011;39 (11):2452-2457.

32. Rolland-Debord C, Bureau C, Poitou T, Belin L, Clavel M, Perbet S, et al. Prevalence and prognosis impact of patient-ventilator asynchrony in early phase of weaning according to two detection methods. Anesthesiology 2017;127(6):989-997.

33. Burns SM. Working with respiratory waveforms: how to use bedside graphics. AACN Clin Issues 2003;14(2):133-144.

34. Mellott KG, Grap MJ, Munro CL, Sessler CN, Wetzel PA. Patientventilator asynchrony: clinical significance and implications for practice. Crit Care Nurse 2009;29(6):41-55

35. Restrepo RD, Khusid F. Essentials of ventilator graphics. Indian J Respir Care 2014;3(1):396-404.

36. Mellema MS. Ventilator waveforms. Top Companion Anim Med 2013;28(3):112-123

37. Dhand R. Ventilator graphics and respiratory mechanics in the patient with obstructive lung disease. Respir Care 2005;50(2):246-259.

38. Lucangelo U, Bernabé F, Blanch L. Respiratory mechanics derived from signals in the ventilator circuit. Respir Care 2005;50(1):55-65.

39. Acute Respiratory Distress Syndrome Network. Ventilation with lower tidal volumes as compared with traditional tidal volumes for acute lung injury and the acute respiratory distress syndrome. N Engl J Med 2000;342:1301-1308.
40. Terragni PP, Filippini C, Slutsky AS, Birocco A, Tenaglia T, Grasso $\mathrm{S}$, et al. Accuracy of plateau pressure and stress index to identify injurious ventilation in patients with acute respiratory distress syndrome. Anesthesiology 2013;119(4):880-889.

41. Malhotra A. Low-tidal-volume ventilation in the acute respiratory distress syndrome. N Engl J Med 2007;357(11):1113-1120.

42. Dellinger RP, Levy MM, Carlet JM, Bion J, Parker MM, Jaeschke R, et al. Surviving Sepsis Campaign: international guidelines for management of severe sepsis and septic shock: 2008. Intensive Care Med 2008;34(1):17-60.

43. Bigatello LM, Davignon KR, Stelfox HT. Respiratory mechanics and ventilator waveforms in the patient with acute lung injury. Respir Care 2005;50(2):235-244.

44. Ranieri VM, Zhang H, Mascia L, Aubin M, Lin CY, Mullen JB, et al. Pressure-time curve predicts minimally injurious ventilatory strategy in an isolated rat lung model. Anesthesiology 2000;93(5):1320-1328.

45. Grasso S, Terragni P, Mascia L, Fanelli V, Quintel M, Herrmann P, et al. Airway pressure-time curve profile (stress index) detects tidal recruitment/hyperinflation in experimental acute lung injury. Crit Care Med 2004;32(4):1018-1027.

46. Ranieri VM, Giuliani R, Fiore T, Dambrosio M, Milic-Emili J. Volume-pressure curve of the respiratory system predicts effects of PEEP in ARDS: "occlusion" versus "constant flow" technique. Am J Respir Crit Care Med 1994;149(1):19-27.

47. Hess DR. Respiratory mechanics in mechanically ventilated patients. Respir Care 2014;59(11):1773-1794.

48. Grasso S, Stripoli T, De Michele M, Bruno F, Moschetta M, Angelelli $\mathrm{G}$, et al. ARDSnet ventilatory protocol and alveolar hyperinflation: role of positive end-expiratory pressure. Am J Respir Crit Care Med 2007;176(8):761-767.

49. Huang Y, Yang Y, Chen Q, Liu S, Liu L, Pan C, et al. Pulmonary acute respiratory distress syndrome: positive end-expiratory pressure titration needs stress index. J Surg Res 2013;185(1):347-352.

50. Ranieri VM, Eissa NT, Corbeil C, Chassé M, Braidy J, Matar N, et al. Effects of positive end-expiratory pressure on alveolar recruitment and gas exchange in patients with the adult respiratory distress syndrome. Am Rev Respir Dis 1991;144(3 Pt 1):544-551.

51. Terragni PP, Rosboch G, Tealdi A, Corno E, Menaldo E, Davini O, et al. Tidal hyperinflation during low tidal volume ventilation in acute respiratory distress syndrome. Am J Respir Crit Care Med 2007;175 (2):160-166

52. Terragni PP, Del Sorbo L, Mascia L, Urbino R, Martin EL, Birocco A, et al. Tidal volume lower than $6 \mathrm{~mL} / \mathrm{kg}$ enhances lung protection: role of extracorporeal carbon dioxide removal. Anesthesiology 2009;111 (4):826-835

53. Chiumello D, Carlesso E, Cadringher P, Caironi P, Valenza F, Polli F, et al. Lung stress and strain during mechanical ventilation for acute respiratory distress syndrome. Am J Respir Crit Care Med 2008;178 (4):346-355

54. Ferrando C, Suárez-Sipmann F, Gutierrez A, Tusman G, Carbonell J, Garcia M, et al. Adjusting tidal volume to stress index in an open lung condition optimizes ventilation and prevents overdistension in an experimental model of lung injury and reduced chest wall compliance. Crit Care 2015; 19(1):9.

55. Suarez-Sipmann F, Böhm SH, Tusman G, Pesch T, Thamm O, Reissmann $\mathrm{H}$, et al. Use of dynamic compliance for open lung positive end-expiratory pressure titration in an experimental study. Crit Care Med 2007;35(1):214-221.

56. Sun XM, Chen GQ, Chen K, Wang YM, He X, Huang HW, et al. Stress index can be accurately and reliably assessed by visually inspecting ventilator waveforms. Respir Care 2018;63(9):1094-1101.

57. Grinnan DC, Truwit JD. Clinical review: respiratory mechanics in spontaneous and assisted ventilation. Crit Care 2005;9(5):472-484 


\section{VENTILATOR GRAPHICS}

58. Marini JJ. Lung mechanics determinations at the bedside: instrumentation and clinical application. Respir Care 1990;35:669-696.

59. Bates JHT, Rossi A, Milic-Emili J. Analysis of the behavior of the respiratory system with constant inspiratory flow. J Appl Physiol 1985;58(6): 1840-1848.

60. Correger E, Murias G, Chacon E, Estruga A, Sales B, Lopez-Aguilar $\mathrm{J}$, et al. Interpretation of ventilator curves in patients with acute respiratory failure. Med Intensiva 2012;36(4):294-306.

61. Lemaire F, Simoneau A, Risara D, Tesseire B, Atlan G, Rapin M. Static pulmonary pressure-volume curve, positive end-expiratory pressure ventilation and gas exchange in acute respiratory failure. Am Rev Respir Dis 1979;119:328.

62. Weiner DJ, Forno E, Sullivan L, Weiner GA, Kurland G. Subjective and objective assessments of flow-volume curve configuration in children and young adults. Ann Am Thorac Soc 2016;13(7):10891095.

63. Karkhanis VS, Desai U, Joshi JM. Flow volume loop as a diagnostic marker. Lung India 2013;30(2):166-168.

64. Amato MB, Barbas CS, Medeiros DM, Magaldi RB, Schettino GP, Lorenzi-Filho G, et al. Effect of a protective-ventilation strategy on mortality in the acute respiratory distress syndrome. N Engl J Med 1998;338(6):347-354.

65. Lu Q, Rouby JJ. Measurement of pressure-volume curves in patients on mechanical ventilation: methods and significance. Crit Care 2000;4 (2):91-100.

66. Rouby JJ, Lu Q, Vieira S. Pressure/volume curves and lung computed tomography in acute respiratory distress syndrome. Eur Respir J 2003;42(Suppl):S27-S36.

67. Hess DR. Recruitment maneuvers and PEEP titration. Respir Care 2015;60(11):1688-1704

68. Harris RS. Pressure-volume curves of the respiratory system. Respir Care 2005;50(1):78-98.

69. Piacentini E, Wysocki M, Blanch L. A new automated method versus continuous positive airway pressure method for measuring pressurevolume curves in patients with acute lung injury. Intensive Care Med 2009;35(3):565-570.

70. Gattinoni L, Pesenti A, Avalli L, Rossi F, Bombino M. Pressure-volume curve of total respiratory system in acute respiratory failure. Computed tomographic scan study. Am Rev Respir Dis 1987;136 (3):730-736.

71. Beydon L, Svantesson C, Brauer K, Lemaire F, Jonson B. Respiratory mechanics in patients ventilated for critical lung disease. Eur Respir J 1996;9(2):262-273.

72. Nunn JF. Elastic resistance to ventilation. In: Lumb A, editors. Nunn's applied respiratory physiology, 8th ed. Philadelphia: Elsevier; 2017:17-31.

\section{Discussion}

Blanch: Thank you very much for this very nice lecture on a difficult topic. I must admit that I learn much more examining waveforms on the computer than when I see the graphics at the bedside. When you start analyzing all of these complex issues, I'm sure you realize your final slide is completely true. So, thank you. I would like to ask on your point about the volume not accounted for tidal volume. In the
73. Maggiore SM, Brochard L. Pressure-volume curve: methods and meaning. Minerva Anestesiol 2001;67(4):228-237.

74. Blanch L, López-Aguilar J, Villagrá A. Bedside evaluation of pressure-volume curves in patients with acute respiratory distress syndrome. Curr Opin Crit Care 2007;13(3):332-337.

75. Kallet RH. Should PEEP titration be based on chest mechanics in patients with ARDS? Respir Care 2016;61(6):876-890.

76. Cabello B, Mancebo J. Work of breathing. Intensive Care Med 2006;32(9):1311-1314.

77. Cohen NH, Schwartz DE. Monitoring the airway and pulmonary function. In: Hagberg CA, editor. Benumof and Hagberg's airway management. 3rd ed. Philadelphia: Elsevier; 2013:998-1017.

78. de Vries H, Jonkman A, Shi Z-H, Spoelstra-de Man A, Heunks L. Assessing breathing effort in mechanical ventilation: physiology and clinical implications. Ann Transl Med 2018;6(19):387.

79. Di Marco F, Centanni S, Bellone A, Messinesi G, Pesci A, Scala R, et al. Optimization of ventilator setting by flow and pressure waveforms analysis during noninvasive ventilation for acute exacerbations of COPD: a multicentric randomized controlled trial. Crit Care 2011;15(6):R283.

80. Longhini F, Colombo D, Pisani L, Idone F, Chun P, Doorduin J, et al. Efficacy of ventilator waveform observation for detection of patientventilator asynchrony during NIV: a multicentre study. ERJ Open Res 2017;3(4):00075-2017.

81. Ramirez II, Arellano DH, Adasme RS, Landeros JM, Salinas FA, Vargas AG, et al. Ability of ICU health-care professionals to identify patient-ventilator asynchrony using waveform analysis. Respir Care 2017;62(2):144-149.

82. Gutierrez G, Ballarino GJ, Turkan H, Abril J, De La Cruz L, Edsall C, et al. Automatic detection of patient-ventilator asynchrony by spectral analysis of airway flow. Crit Care 2011;15(4):R167.

83. Sinderby C, Liu S, Colombo D, Camarotta G, Slutsky AS, Navalesi P, et al. An automated and standardized neural index to quantify patientventilator interaction. Crit Care 2013;17(5):R239.

84. Clavieras N, Wysocki M, Coisel Y, Galia F, Conseil M, Chanques $\mathrm{G}$, et al. Prospective randomized crossover study of a new closed-loop control system versus pressure support during weaning from mechanical ventilation. Anesthesiology 2013;119 (3):631-641.

85. Branson RD, Johannigman JA. The role of ventilator graphics when setting dual-control modes. Respir Care 2005;50(2):187-201.

86. Singh PM, Borle A, Trikha A. Newer nonconventional modes of mechanical ventilation. J Emerg Trauma Shock 2014;7(3):222227. presence of leaks, ventilators reset to zero the expiratory tidal volume to avoid the drift on the depicted waveform. A non-identified leak around the endotracheal tube cuff is a risk for unplanned extubation.

Dexter: You make a valid point. This discussion continues to go back to the main point which is that, while ventilator manufacturers continue to advance the design of ventilators, it's not always in the best interest of the patients or us as the clinicians. I ask the question, are these advancements actually causing more misuse at the bedside than helping to improve patient care?

MacIntyre: Amanda, you covered a lot of ground but I'd like to go back to a concept that I've become increasingly intrigued with - the stress index (SI) and its second cousin, driving pressure, as a way of looking at mechanics during tidal breath delivery. The shape of the pressure waveform and the amount of pressure during that 


\section{VENTILATOR GRAPHICS}

tidal breath delivery could be very useful to optimize PEEP and tidal volume settings. I know there are people around this table who are quite experienced in this and I'd be curious to know, is there a future for this being automated? Providing an SI, providing driving pressure? That's going to require a ventilator or a clinician to give a passive, volume-controlled breath with a constant flow. Under these conditions, the shape of the pressure-time tracing would be driven by compliance changes during the breath. If recruitment is occurring, the compliance increases, if overdistention is occurring, compliance decreases, if neither is occurring, compliance remains constant. Driving pressure (Pplat-PEEP) is another way of assessing compliance during the tidal breath delivery. I think of these as tools to fine tune the ventilator settings (the millennials have no idea that this term "fine tuning" is from the old television sets where you would set the channel with a course knob and then use another knob to fine tune it to where you'd get a good signal). That was a long-winded way of asking you and the group here who know a lot about this, is the SI and driving pressure the tool of the $21^{\text {st }}$ century to really optimize our ventilator settings?

*Hess: I'll chime in. There is one ventilator manufacturer that does calculate and display the SI. You are correct, however, in that it doesn't make any sense in pressure control or in pressure support. It has to be constant flow volume-controlled ventilation with no active inspiratory efforts by the patient. I have seen it used incorrectly at the bedside where the patient is making an effort and that looks like overdistension. As you probably know, I've been a fan of the SI over the years, but there are problems with its use if you are not careful in understanding the pitfalls at the bedside.
MacIntyre: I totally agree. This has to be a volume-controlled breath with a constant flow. This can be clinician set or maybe the machine can do it automatically with a kind of a test breath from which it makes the calculations. But is it worth the trouble? You can give patients a little extra sedation or a little paralytic if needed.

Piraino: Just a comment about driving pressure, it may be an underutilized setting in volume-control, but we use the $0.2-0.3 \mathrm{~s}$ pause in volume-control. If your patient is passive you get an accurate measurement of Pplat in real time. And some ventilators won't actually read a real-time Pplat measurement unless you have 0 flow. When you set this 0.2 or $0.3 \mathrm{~s}$ pause, you have Pplat reading on the ventilator all the time and for the electronic record you can actually pull these data and have it calculate driving pressure for you in real time. I think that's probably closer to reality. The situation with the SI is more challenging because even on the ventilators that have it, SI requires that you have a much lower flow than you probably should set in most adult patients. We routinely set between 50 and $60 \mathrm{~L} / \mathrm{min}$ of inspiratory flow in our patients, but the maneuver requires it to be closer to 40 or 50 . The inspiratory time has to be about $0.8 \mathrm{~s}$ in total. The reason why you need to slow down the flow, as Dean [Hess] mentioned, the more rapidly that flow goes in the more you see the resistive pressure, and the elastic pressure is what you really want to capture. It would be easier if it was an automated maneuver where you push the button, it lowers the flow, does the maneuver, and gives you a number rather than having a feature on a ventilator that I think most clinicians don't understand how to properly use.

MacIntyre: Tom [Piraino], I completely agree with you. It always surprises me that the ventilator companies have been so reluctant to put short pauses in. Not necessarily with every breath but maybe applied every 5 or 10 minutes. The manufacturers always seem to fall back on the notion that it'd never get through the FDA and I think that's crazy. We sit here and preach lung protective ventilation with small tidal volumes, appropriate PEEP and limiting Pplat and maybe limiting driving pressures and optimizing SI, and yet we cannot get the ventilator to give us the critical Pplat measurement. I find it amazing that one of the cornerstones of lung protective ventilation is something the ventilator companies will not help us with. I just don't understand the reluctance.

Schmidt: One thing about getting useful information out of the waveforms is that the more controlled the inputs are, the more interpretable are the outputs. And when we use an inspiratory flow profile that is not square it makes it harder to get out useful information. My question is, why ever use a decelerating flow profile, which you showed in some of your slides? Why not use a square profile?

Dexter: For me, the biggest thing is always patient comfort. I always choose the flow profile based on this comfortability factor. Through trial and error, I have seen patients look more comfortable with a decelerating flow than in a square waveform pattern. In my opinion, flow profile is more commonly set for patient comfort than for measuring mechanics on the ventilator.

Piraino: If your patient is complaining about comfort, they're probably not ideal to be in a mode where the clinician control aspects of the flow to get the respiratory mechanics information. But the reality of it is that when patients are in controlled ventilation and are being passively ventilated, many clinicians choose this decelerating flow pattern, which again gives 


\section{VENTILATOR GRAPHICS}

you less reliable or accurate information or requires estimation rather than accurate measurements of respiratory mechanics. And a lot of it comes down to fear of the peak pressure rather than understanding the fact that peak pressure is a resistive force which if you start implementing pause $(0.2-0.3 \mathrm{~s})$ maneuvers you realize the pressure being felt by the lung is actually $20 \mathrm{~cm} \mathrm{H}_{2} \mathrm{O}$, not 28 or $30 \mathrm{~cm} \mathrm{H}_{2} \mathrm{O}$ when you actually distinguish the two pressures.

Dexter: I think it also comes down to the comfort and competence of the RT setting up the ventilator as well.

*Hess: An observation I've made is that a lot of nurses, RTs, and physicians like the descending ramp because the peak pressures are lower. There is some evidence at least in animal models that there might be more lung injury if you have a higher flow earlier in the breath. Neil [MacIntyre], I think you were the one who told me about this a few years ago; that a descending ramp of flow might be more injurious at least in an animal model.

MacIntyre: Most of the comments I made were speculative but it is interesting that there is at least one animal study ${ }^{1}$ that said acceleration may be an additional injurious factor in the lung and that you get less injury with a very slow flow and low acceleration forces for the same volume than if you ram it in quickly with high acceleration force. Now again, translating that to the clinical setting is fraught with errors, but it is an intriguing thought.

Blanch: One important point is to make the right measurements for driving pressure. Plateau pressure must be obtained with the patient relaxed. Otherwise the value of driving pressure could be incorrectly estimated. In patients presenting reverse triggering (a diaphragm contraction triggered by a passive lung insufflation), the correct measurement of plateau pressure is no longer possible. In conditions of flow starvation, the measurement of plateau pressure is also limited. In this condition, I prefer decelerating flow modes because there is a better matching between ventilator and patient needs, as you Neil demonstrated in the past.

MacIntyre: I don't worry about square and decelerating patterns because we tend to use pressure-targeted modes of ventilation and let the patient decide the flow pattern. Just to clarify. And I want to re-emphasize a point Tom made that I think is really important, which is that people throw their hands up in the air and say you can't get Pplat during pressure-targeted forms of ventilation. You certainly can as Tom pointed out because most modern machines allow inspiratory pauses during pressure control. Indeed, in pressure control, sometimes the breath lasts long enough goes to 0 flow anyway and you have a Pplat.

Dexter: I think that also goes back to understanding each of the numerous modes of mechanical ventilation, in detail, and there are a lot of RTs who misunderstand that concept.

Scott: First of all Amanda, very nice job. I'd like to pivot to the concept of the inability to interpret ventilator graphics by RTs and other practitioners. As for me, I've been an RT for 18 years and was trained on ventilators that didn't have graphic packages on them. I was told by my trainer that this was the best ever invented and that you could ventilate anybody with it, but it didn't have a graphics package. Obviously there are a lot of clinicians out there who were not formally trained and then over time any existing training didn't stick or there was no emphasis. The question I have is, moving forward, how do we change this? I still, in 2019, see a lot of clinicians (I would argue the majority of clinicians) who are not competent in interpreting ventilator graphics. Should we put more emphasis on the education, or on the value, or on both?

Dexter: Personally, as a respiratory therapy educator, I would put more emphasis on education. I'm also a certified simulation educator, so I use simulated settings quite often to test students and educate them on concepts such as ventilator asynchrony and ventilator graphics. I think this topic could very easily be incorporated into any formal training program. It could even be incorporated during training at the bedside. In my literature review, I found few facilities in the U.S. currently incorporating ventilator graphics education into their ventilator rounds at the bedside. So for me, it would be more of an emphasis on the significant need for more education.

Smallwood: I'd like to add a comment to the discussion. The emphasis should be on the desired effect or perhaps the intervention you plan to offer. The bedside clinician, whether it's an $\mathrm{RT}$, an ICU physician, whomever, is not going to care, and perhaps justifiably so, about waveform analysis unless there are specific things, or actions, or interventions that can be offered and acted upon to change and hopefully improve patient care. For instance, does our interpretation of the waveform and detection of asynchrony lead us to change a setting on the ventilator? Change the sedation dosing? Or something else? Another thing to consider is that it isn't practical to have a clinician stare at waveforms 24 hours in the day watching for a couple strange blips. We need help. What I think we need to do, at the same time we encourage ourselves to become experts on waveform analysis and understanding the physiologic im- 


\section{VENTILATOR GRAPHICS}

plications is to see out computerized assistance. Perhaps one day a system will be so good as to process, diagnose and recommend change in care, but for now what we need is a system to flag a patient as potentially abnormal and saying to us, the clinicians, 'hey, what do you think of this?' Because in our hearts we need to be physiologists at the bedside to understand problems and offer appropriate interventions. We have the knowledge and experience that an automated system will not have. In general though, what we need are actionable insights. We need to be able to say, 'look for this waveform, look for this feature on that waveform, do this to change care, and it will likely have this beneficial impact on the patient.' Because without a clear directive that can guide practice, I'm not sure all this effort will turn out to be worth it.

Walsh: I'd like to follow what Brady [Scott] mentioned, I trained in the same decade as he did where we didn't have ventilator graphics and so our clinical assessment skills are perhaps superior than today's clinicians being trained, because they're being taught the graphics and not necessarily the patient assessment skills. I think if we do train them on graphics we cannot drop the patient assessment piece of it, that's not an equal trade off. My last comment, and
Craig [Smallwood] hit on this, why don't we actually have computer interpretations of ventilator waveforms? It's driven me crazy, we have them for electrocardiography, we have monitors that will alarm arrythmias, but we don't have a basic simple thing like restrictive vs obstructive.

\section{REFERENCE}

1. Rich PB, Reickert CA, Sawada S, Awad SS, Lynch WR, Johnson KJ, Hirschl RB. Effect of rate and inspiratory flow on ventilatorinduced lung injury. J Trauma 2000;49 (5):903-911.

*Dean R Hess PhD RRT FAARC is Managing Editor of RESPIRATORY CARE.

This article is approved for Continuing Respiratory Care Education credit. For information and to obtain your CRCE

(free to AARC members) visit

www.rcjournal.com 